SCIREA Journal of Information Science

and Systems Science

http://www.scirea.org/journal/ISSS

February 12, 2022

Volume 6, Issue 1, February 2022

https://doi.org/10.54647/isss 12194

\title{
Regeneration by Design: Leveraging social narratives, to help create improved and sustainable lifestyles.
}

\author{
Chris D Beaumont ${ }^{1}$, Darrell Berry ${ }^{2}$, John Ricketts ${ }^{3}$ \\ ${ }^{1}$ Institute for Future Initiatives, LifeStyle byDesign, The University of Tokyo \\ 7-3-1 Hongo, Bunkyo-ku, Tokyo 113-0033, Japan \\ 2 Significance Systems, Brighton, UK \\ ${ }^{3}$ Significance Systems, Sydney NSW 2069, Australia. \\ Email: cbeaumont@g.ecc.u-tokyo.ac.jp (Chris D Beaumont)
}

\begin{abstract}
The social systems of many countries are under stress due to longevity and low birth rates. Healthcare has evolved from a treatment orientation to a prophylactic stance. Therefore, greater consideration must be given to lifestyle behaviour and life satisfaction. This has been recently further deepened by the COVID-19 pandemic which necessitated many changes in daily life and moved health, in the broadest sense, to the top of the agenda.

This paper tracks key lifestyle narratives since June 2019, comparing Japan and the UK, through to December 2021. It provides a Virtual Living Lab monitoring what people think and feel is important during a period of unparalleled change. It demonstrates how state-of-theart communications science, leveraging AI and Big Data, can 'engage with engagement' and communicate in a relevant and credible manner. During a period of volatility and uncertainty, it is especially important to understand the context for Strategic Leadership Narratives to
\end{abstract}


credibly effect change in attitudes and behaviour. Similarly, leveraging existing narratives can intentionally enhance the diffusion of new ideas and behaviours.

Keywords: Lifestyle, Empowerment, Context, Optimistic, Quality of Life (QOL), Regeneration, Technology, Big Data, AI, Design thinking, Informed Choice, Diffusion of Innovation, Strategic Leadership Narratives, Engagement, Sustainable Age, Multidisciplinary, Social innovation, Policy, Purpose

\section{Context for Change}

COVID-19 has shown a resilience of self and community and going forward any 'Regeneration by Design' that creates sustainable lifestyles will need to provide a simple and coherent leadership narrative that inspires and motivates creative thinking. Leaders will be united on the purpose, and not united on the framework. Their positive focus will naturally be driven by timeless needs dignified by conditions, ageing demography and cultural considerations. There is a new urgency for the world; the COVID-19 pandemic has shown us in hard way that many things were broken and there is a need to reset. Such is the nature and rate of change that all institutions, public or private companies, need a strategic leadership narrative [1] that inspires their people and moves them in a consistent and coherent manner to make better outcomes.

Our lives at both the micro and the macro level are being transformed by technology, interconnectedness, and economic growth. But transformation brings uncertainty and, for many, instability. Innovation has driven growth but also leads to greater instability and can be viewed as 'Disruption by Design' where previous standards have been disrupted by new norms. The cases of Uber, Netflix, Amazon,...., for example, demonstrate how a customercentric focus, allowed them to replace incumbent category leaders. The internet can connect people but does not necessarily provide jobs. Yet transformation is the essence of life itself and, as humans, we manifest our transformations through changes in our lifestyles and what is important to us. We share ideas and truths, experiences, and beliefs through our conversations, which have been materially affected by social media in recent years. By doing so we can experience transformation in a positive way, with personal growth and evolution. 
At the macro level, there is general agreement about some of the global issues that face humans today. Many of these problems are too big to be solved by a single company or country but demand cross-border, multi-disciplinary collaboration involving public and private sectors, alike. Be it climate change, inequality, diversity, ..., healthcare, there are well established frameworks to facilitate co-creation, objective priority setting, and benchmarking. For example, the Sustainable Development Goals (SDG's) [2] provide a coherent framework for intentional, priority setting and benchmarking. The World in 2050 [3] is a global research initiative in support of a successful implementation of the United Nations' 2030 Agenda. The objective of TWI2050 is to provide the fact-based knowledge to support the policy process and implementation of the SDGs.TWI2050, by design, brings together leading policymakers, analysts, modeling, and analytical teams to collaborate in developing pathways toward sustainable futures and policy frameworks for achieving the needed transformational change. With a focus on emissions, the COP26 UN Climate Summit [4], only guaranteed a dialogue between rich and poor countries instead of the latter's wish for a financing facility, since much of the climate problems were historically caused by the already industrialised nations. However, broadly accepted frameworks such as SDG's can help change the purpose of business.

Sustainable finance is at the heart of addressing the problems of climate change. The popularity of ESG (environmental, social, and governance), investing reflects the trend, across borders, towards portfolio decarbonisation. The financial community are rewarding firms that focus on the "E" regarding the critical current, global, issues of climate change and diversity we face today. At a corporate level it is becoming more widely agreed that companies which focus on ESG concerns can produce positive impacts for the firms. Unfortunately to date, there are no consistent and coherent rating metrics, or explicit and practical consideration of appropriate value drivers; the focus being primarily driven by the investor community with no objective assessment that adding an ethical dimension can enhance returns. Progress needs a positive mindset and a new vocabulary such as linking ESG to value creation rather than compliance. This will be greatly helped that a regulatory framework is being established to monitor the transparency of ESG ratings [5]. In the same vein, short-term opportunism is likely to be restricted by a consortium of financial institutions who have created the ESG Book; a free information platform that makes comparable data readily available for all stakeholders [6]. It would be further helped if financial experts were to take a broader position and no longer have a singular focus on shareholders but look at 
stakeholder capitalism and regenerative finance, and not the traditional ROI measures. Implicitly, regenerating society will help go beyond a sustainable (survival) stance to think of 'thrivability' (succeeding). Regenerative has become the new buzzword in the fashion industry replacing sustainability [7].

In times of crisis and uncertainty people often turn to brands and businesses they trust. The COVID pandemic has both magnified and accelerated this trend. Although greater data and information is readily available, people do not feel better informed rather there is an increasing concern about what information is correct. Edelman's annual research [8] refers to year of the pandemic being characterised by an "epidemic of misinformation...... in an environment of information bankruptcy”. People now expect businesses to play a bigger role to help society, communities, environments in dire need of support, and rebuilding. Businesses which do not rise to the challenge are at serious risk of becoming irrelevant. Mark Read (CEO, WPP), noted that more and more companies and brands are looking to guide corporate growth by a higher societal purpose [9]. Generally, how they can make a material difference to their communities, and how their products and services can have a less detrimental effect on the world.

This purpose explicitly recognizes the importance of corporate transparency in building trust. First it demands leadership, who have a vision and the passion and persuasion to clearly commit their strategic leadership narrative to a better future. It involves ethical collaboration, action by design that is intentional and proactive. A case in point can be summed up by being "Net Positive" [10]. The title of this seminal book in which author and former Unilever CEO Paul Polman says it is business (leaders) who must step up! To thrive today and tomorrow, companies must become 'net positive'-giving more to the world than they take. Although a Harvard Business book it is for everyone, showing how we can help us reset our worlds direction for future generations, and take a more positive stance than is implicit in 'Net Zero' [11]. If transnational CEOs follow Polman's courageous and principled strategy the governments will also respond to a more equitable approach. Unilever recognised the importance of sustainability and took a coherent leadership perspective beyond CSR. This has culminated in the Unilever Sustainable Living Plan (USLP) which created has over a decade of transformation across their value chain, benefiting social, environmental, and economic performance. A journey that is now tracked by the Unilever Compass that directs their corporate and is a benchmark for others. It is hoped this clear strategic leadership narrative is the start of a 'net positive' movement that moves 
the sustainability argument forward with focused action. It can be the 'North Star' where every enterprise improves the well-being for everyone.

Data is ever increasing but so is disinformation / misinformation to the extent that people do not know what to believe and feel increasingly ill-informed. The need for a cross-border, regulatory framework for ESG metrics to stop the growth of 'greenwashing' where enterprise overstate their environmental activities. Marketing image,'green washing', for some takes precedence over substance, and long-term commitment to doing the right thing!

Co-ordinated international action has been tested and seen to fail regarding COVID-19. Yet Polman [op cit] argues that "Culture is the glue", the consistency that maintains people on the same page. It gets rejuvenated especially during periods of volatility. Fueled by (anti) social media, increased inequality, and governments that have often been caught off guard and unprepared, the COVID-19 became an internet virus as well as a biospheric virus. This means that minds have been altered, opinions changed, and attitudes adjusted. Already social and political commentators [12] are referring to the tectonic shift created by the pandemic in terms of different era BC, DC, and AC (Before- During- and After Covid-19).

Aligning with mega trends is not a new strategic driver. It can be very effective if done in a credible and meaningful manner. One such theme, Corporate Social Responsibility (CSR) was popularized at the start of this millennium. Social responsibility demonstrating a commitment to improve in the world is productive, positive work in respect to the environment. Concerned with achieving long term goals socially responsible corporations could attract / retain good people. However, the CSR initiatives were mere marketing gloss than being strategically focused [13]. It was not compulsory but perhaps now CSR is being replaced by ESG as the necessity of materiality standards gain acceptance, with a focus, from a corporate perspective, to help attract investors, which is not the case in the capital markets[14].

While nobody can question the need for better responsibility and governance the jury is out on whether this is something that is practical and can provide meaningful metrics that discriminate the good and the bad. The answer would be yes if the principles of sustainability were central to the company's business strategy. Such a perspective is labelled a 'regenerative mindset' [15], when one views the health of the world as symbiotic relationships between humans and other livings thins and our ecosystems. This explicitly considers social and environmental challenges to be interrelated and progress will demand rebalancing to restore the interrelationships. 
Increasingly there is objective, empirical evidence that improved and sustainable bottom lines can come from helping communities and the environment. Polman from his time leading Unilever is perhaps the most visible with the broad response to the publication of Net Positive [16]. In addition, Bain \& Co., recent survey of more than 8,000 European consumers and over 60 brands across eight consumer goods categories found that brands that scored highest on sustainability 'elements of value' generated five times the revenue growth of companies scoring lowest [17].

At the same time, there is growing evidence that the current health systems of nations around the world will be unsustainable if unchanged over the next 15 years. Globally, healthcare is threatened by a confluence of powerful trends - increasing demand, rising costs, uneven quality, misaligned incentives. If ignored, they will overwhelm health systems, creating massive financial burdens for individual countries and devastating health problems for the individuals who live in them. Governments are encouraging individuals to take more responsibility for their health, and this is creating a mindset shift from healthcare for treatment to a more lifestyle orientated, and preventative stance, which further increases interest in the broad area of health and well-being. This represents a fundamental shift from the WHO's 1948 definition [18] and entered into force on 7 April 1948] of healthcare which was wholly orientated around treatment.

A key element going forward will be to have sustainability as a central theme, but also try to empower individuals they can go beyond to personally thrive; 'net positive'! Wellness is ontrend globally, not simply because of the ageing demographics in many mature markets but because of changing attitudes and behaviours amongst the young, who are looking for 'healthier' options, reflective of seeking a healthy and balanced life. While COVID-19 has made everyone more concerned about health it has also changed people's fitness habits [19]. Significantly, health is no longer about illness; it is about wellness. It is increasingly a daily concern, thinking about diet and activity with a focus on tomorrow and an enduring healthy lifestyle. A mindset thinking about 'healthspan' demands a pedagogic stance and clear communications to empower. Personal health and sustainability are complimentary triggers to the boom in plant-based meat alternatives, driving a new perceived value proposition [20]. An ethical and cultural stance driven by the new millennials [21].

Laddering up the idea of personal health is encapsulated by the notion of life satisfaction. It is widely viewed as a common variable on which to make decisions informed by wellbeing evidence. The question used to assess life satisfaction in the UK, within the 'Measuring 
National Wellbeing' framework developed by the Office for National Statistics is: "Overall, how satisfied are you with your life nowadays?" Respondents answer on a scale from zero to ten, where zero means 'not at all satisfied' and ten means 'completely satisfied'. Life satisfaction is a simple question (not an index or equation). Extensive research shows that subjective experience is an objective phenomenon. Self-reports correlate with electrical activity in the relevant areas in the brain. They predict longevity, job quitting, marital breakup, childbearing, productivity, voting, ...., driving safety. Life satisfaction is easy to say and difficult to act on consistently and coherently. Richer individuals are happier than poorer individuals. Yet, as countries grow richer over time, they do not seem to become happier. The so-called happiness-income, 'Easterlin Paradox' [22], can be explained by your income making you happy but me unhappy.

Most people now realise that economic growth, however desirable, cannot solve all our problems. Instead, we need philosophy and science that encompass a broader range of human needs and experiences. We must accept that the aggregate, top-down, GDP statistic does not measure the health of society [23]. Indeed, it measures everything in short, except what makes life worthwhile! Taking a 'measure what we treasure' stance would be a major step in creating a more inclusive and equitable society [24], from the bottom-up. So, we might look to consider the 'Gross Domestic of Well-Being' as a better metric to assess how well society is regenerating $\mathrm{AC}[12]$ ?! For some it comes down to a more holistic focus on the; ' $\mathrm{S}$ ' in ESG [25], which is underpinned by strong governance and implicitly reflects social considerations.

The ethics of life satisfaction could be grounded easily by making a radical new goal for society. That goal is the happiness of the people! [26]. Simple, but with powerful implications for how we should live and how policymakers should act on everybody's behalf. We can identify which aspects of life affect Life Satisfaction [27] most and this can help drive policy. Such policy changes then could be calibrated for cost-benefit.

The pandemic demands a reset towards the regenerative society where, if COVID-19 has enduring impacts one might be in the recognition of community value. Social relationships are essential to life satisfaction - indeed, research identifies a 'well-being dividend' [28] that social connectedness correlates more strongly with life satisfaction than social or economic characteristics such as long-term illness, unemployment or being a single parent [29]. Those who report highest levels are typically those empowered to make a change in their community; understand tools /networks that can assist them. Paradoxically those with the greatest need are typically the quietist, so it especially important to nurture rather than neglect through 
sustained, credible engagement. The Connected Communities study demonstrated how focused action could lead to material benefits to enhance the resilience of local communities. It indicated that social relations could be strengthened to create value in different ways. They identified four 'dividends' [29]:

1. The well-being dividend- as noted above;

2. The citizenship dividend- untapped energy within local communities from the potential of relationships between people;

3. The capacity dividend- focusing resources on networks, rather than on individuals have greater effects since they permeatesocial networks;

4. The economic dividend- investing in interventions which build social relationships can improve employability, improve health, and thus create savings in healthcare costs.

These demand a multi-disciplinary approach, anywhere, to improve QOL.

Going forward we can envisage that the future of healthcare is going to be increasingly preventative, personalised and precise, but more remote leveraging tele-medicine and AI platforms such as Beomni [30]. Mobile apps, genetic testing, 3D printing, and advanced screenings are just some of the new technologies producing biometric data on an unprecedented scale. A case in point is the idea of 'in-body hospitals' which are likely to be realized by 2045 [31]. At the Center of Innovation (COI) program's Center of Open Innovation Network for Smart Health, researchers are working to develop microscopic capsule nanomachines containing various sensors and drugs that can travel to all parts of the body through the blood. These devices may help establish a new type of medicine that can detect and treat diseases at very early stages. The researchers aim to realize a super-aged, society in which individuals are free from the physical and economic burden and anxiety associated with serious illness - a society in which everyone can enjoy guaranteed health. Currently, the leading causes of death among Japanese people are cancer, heart diseases, and cerebrovascular diseases. Although improved treatments are being established, the anxiety of hospitalization and the high cost of medical care associated with treatment are obvious macro socio-economic concerns. Critically, the aging of society is radically changing the "mind of the market" and the calculus of supply and demand [32]. Japan's response to its' rapidly aging and declining population will be watched by policymakers around the world.

However, this paper focuses more on the necessary social and communication considerations to effect change and realise sustainable regeneration. The COVID-19 crisis provides an opportunity to transform and demands that we are bold - we should make the future better not 
just safer! Technology can greatly help just as machines helped empower and lead to social progress in the Industrial Age. One needs to think less about AI and AR but how we can augment humanity to actualize sustainable regeneration. To do this, in the Sustainable Age, leaders across the board will need to take a customer-, personal- centric, agile approach to excite and attract participation / customers, as well as to reassure them. The current popularity of the notion of the 'metaverse' [33], is considered a transitory distraction and only indicative of the technological evolution of the internet, to 3-D virtual environments. It remains to be seen if it is over-hyped like Second Life, the Linden dollar (L\$), and personal avatars early in the millennium?! Most certainly if such technology was more narrowcast it could create material benefits such as in the therapeutic context. More critically, and grounded, is the fact that intentionally, by design, with intent and purpose, we can measure life satisfaction; we can improve life satisfaction and we can make society stronger.

\section{By Design}

Design thinking is about making intent real with a commitment to optimize and prioritize, while enabling creative thinking / Imagineering to effectively move from 'what is' to 'what can be'. It is a truism, of clarity, that things work better when everything is purposefully coordinated, for a purpose. There is usually no Roadmap for the destination, but a demand for objectivity, focus and clear purpose. The process starts by understanding the need. The context for societal reset, and aging demographics provides mega-trends and insight for innovative thinking, concept development, prototyping before scaling for effect. In the next section the Lifestyle by Design initiative outlines some of the approaches that can be practically used. Specific consideration is given to the experience strategy and management benefits of design thinking since it is anchored at the intersection of business and design innovation. (A more comprehensive, but abstract, overview of potential research methods is provided by Hanington and Bella [34]. Design thinking is gaining broad acceptance since it has been shown to fuel the innovation success rate in business. COVID-19 raised the of doing good and elevating the human experience to address societal problems; the establishment of Ethos [35] is a case in point to focus on the customer experience by design. Even in the short-term and every day, recent research [36] has shown that being intentional about one's leisure time and planning time-off can obviate burn-out. 
Such a flexible approach is ideal given that the societal and global challenges and opportunities demand a collaborative and multi-disciplinary stance, enhanced by interconnectivity and a questioning stance. "The social challenges that we are grappling with are nested within our environmental ones, carbon emissions are intertwined with community health; biodiversity with social justice, and so on." [37]. Warden [37] outlines 8 design principles to empower change agents to fuel regenerative practice by taking a holistic and collaborative stance, which is the antithesis of having a framework, with its' inherent problems to empower creative thinking.. A key component of which is to create challenging questions that can broaden debate:

i. Start with place and context

ii. Seek different perspectives

iii. Build capability and reciprocity

iv. Take a nested systems view of success and consequence

v. Design for circularity and circulation

vi. Create space for emergence

vii. Design from a hopeful vision of the future

viii. Work on the inside as well as the outside

A Key Success Factor (KSF) for design thinking to make a difference is to ensure that the approach goes beyond insights, at the outset, but embraces feedback from users during the innovation process. A tangible example of this is with the Living Lab approach [38].

\section{LifestylebyDesign}

LifeStyle by Design, at The University of Tokyo, seeks to leverage design thinking to promote and deliver a healthier Lifestyle. It seeks through open innovation to create new considerations to the physical, nutritional, and social needs of an individual's balance, so to enhance their QOL. It has collaborated with the public and private sector in its own Living Lab [39]. In 'Imagineering the Future', the basic premise is that the best way to imagine the future is to create it. For many, leadership is not about being able to answer people's questions but being able to pose great questions! If from the point of view of lifestyle by design, we imagine a future say 50 years ahead who's going to be in charge; how do we work; how do we talk to each other; which companies will be winners? To answer this, we're not constrained by today, and indeed there can be no correct answer but establishing clarity can 
create a point of view. What we should envision, in the Sustainable Age [40], if we Fast Forward, is a more caring society. A society, which at the macro level, has three fundamental pillars. These are food, health, and well-being. Each of which are important and ongoing areas of research within the lifestyle by design unit.

Japan provides a unique context for the LifeStyle by Design initiative: super aging. A challenge that will then affect mature and emerging countries soon. Success will enable ideas to be exported; 'Created in Japan for the world's people'. The post-war economic miracle in Japan has been written about extensively but the parallel progress in sustaining a health improvement in society is also remarkable as noted Takemi, in 2021, in his forward to 'Health in Japan" [41].

From a technological perspective there is a coherent vision of Society 5.0 [42]: "A humancentered society that balances economic advancement with the resolution of social problems by a system that highly integrates cyberspace and physical space." Thus, Japan is well suited for societal experimentation, and a vision for an aged society which focuses on 'thrivability' rather than sustainability. Such an attitude would be consistent with regeneration notion of the RSA [43] and Polman's [10] 'Net Positive' perspectives.

The structure of the Japanese family [44] has been transformed significantly in recent decades. Since 1980, the average number of members, per household, has halved, while the number with an aged member has doubled. Most significantly the 3-generation household has reduced from 50\%, in 1980, to only just above $10 \%$ in 2017 [45]. Structural dynamics that will no doubt have contributed to the dramatic rise in mental health conditions due to the covid-19 pandemic. Cable et al., [46] provide a timely warning of the implications on mental well-being due to the long-term structural change in the household structure, and social fragmentation. Significantly the authors note how important Japanese cultural determinants are in influencing behaviour. [47 \& 48]. The severity of psychological stress associated with COVID-19 prevention measures, in Japan, has been shown to be associated with a disruption of core values. However, a similar study in the US found no such association between the burden of preventative measures and the disruption of core beliefs. This led researchers at Tohoku University to suggest the results in Japan were "unique to the population of Japan" [49]. At the same time, social distancing has explicitly increased a sense of loneliness as people's have been unable to get together and especially eat together since widely accepted that communal eating helps social bonding and building personal relationships [50] has shown 
that the menu itself plays an important role itself in creating a sense of inclusiveness, or not, amongst diverse race and ethnicity.

This paper consistently tracks the same lifestyle narratives in Japan and the UK. Both are well-developed countries with a well-established nation health service. "Japan is not an outlier-it is a harbinger." [51]. That said, it was also felt that culture would play an important role in the diffusion of new ideas. Geert Hofstede's [52] seminal work which made him the most-cited European social scientist, demonstrated at the early stages of globalization; "National Culture cannot be changed, but you should understand and respect it." Figure 1 shows the relative cultural scores comparing Japan and the UK on the Hofstede dimensions. Japan is weaker in terms of individualism but takes a more risk-averse and long-term stance when compared with the UK. Japan is also more male orientated with a higher power distance orientation suggestive of the greater importance attached to hierarchy in decision-making. Of cultural interest, in the context of improving a sense of personal well-being is the Japanese concept of Ikigai (Figure 2). Literally, iki= life, alive; and gai= benefit, worth, so it is akin to the western notion of 'reason for being', but much deeper since connoting purpose of life. It is increasingly being considered by westerners, who consider it an important element of Japanese longevity [53].

\section{Japan $\times$ United Kingdom *}

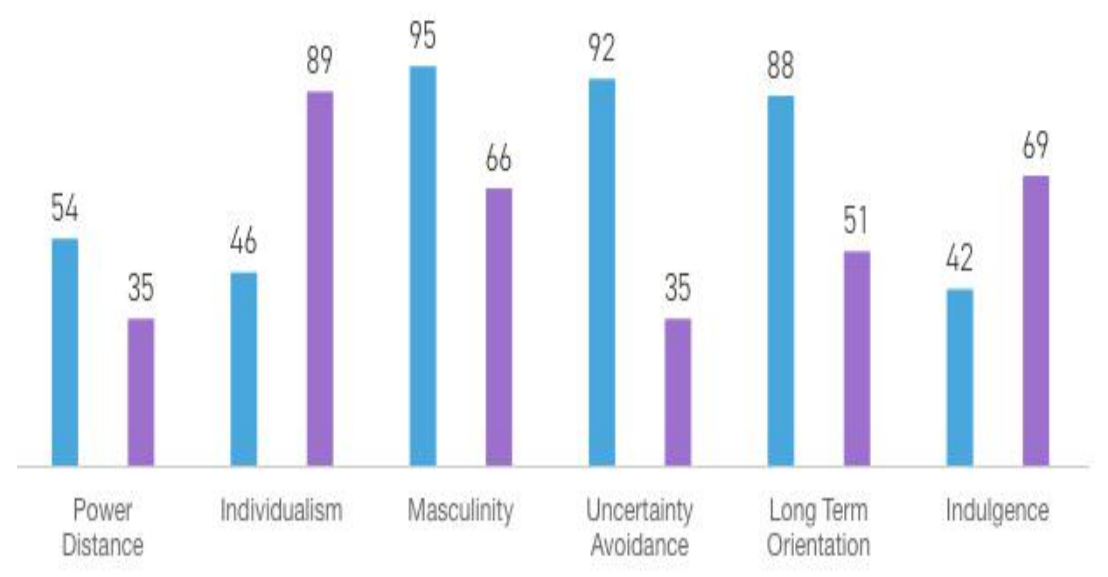

Figure 1 : Hofstede's Dimensions of Culture- Japan \& UK 


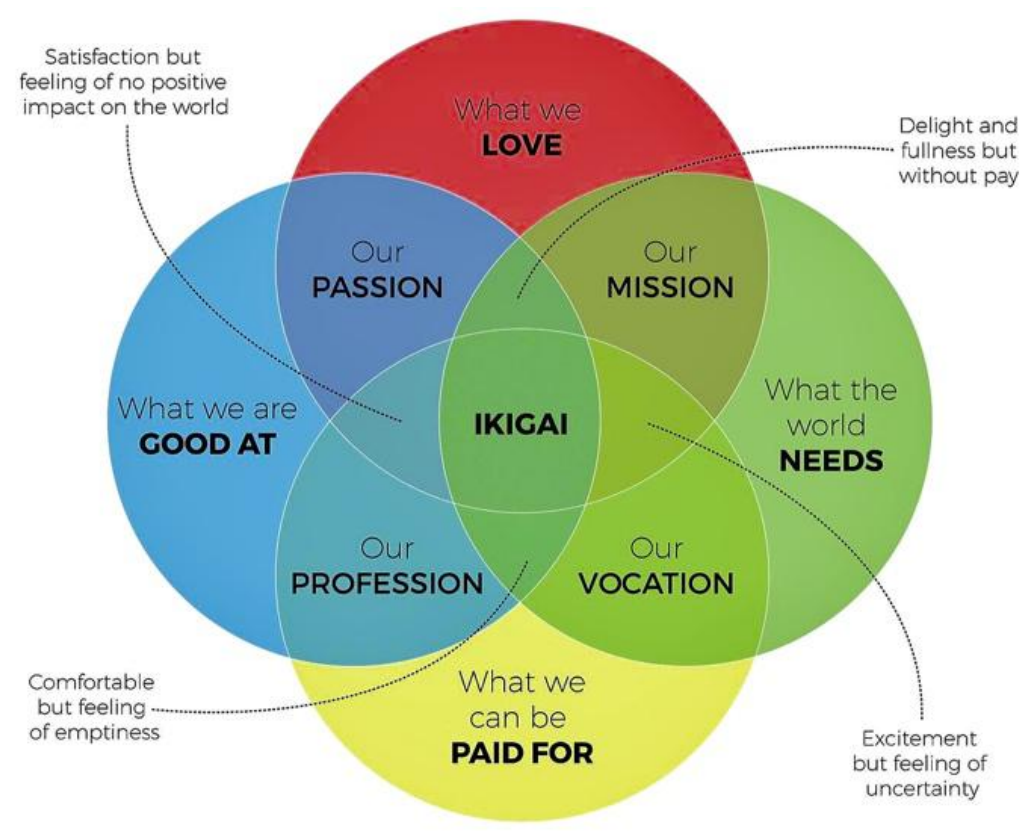

Figure 2: Ikigai. Japanese concept of 'a reason for being'.

COVID-19 has seen different and changing solutions, by different countries, since the pandemic outbreak in December 2019. It has demonstrated that only strong nation states can insist on sacrifices from their people. For some, nationalism is viewed as critical to addressing global crises [54].That said, there has been minimal co-ordinated policy and for some cultural tightness has played a part [55] and that collectivist countries performed the best [56]. The dimensions of national culture, in the Hofstede model, impacted the COVID infection rates, especially regarding individualism and indulgence. COVID-19 has shown that culture shapes both policy and personal decisions [57]. Others have noted with concern that inequality is being magnified by the deployment of vaccines and that will have a detrimental effect on everyone, prolonging the pandemic and slowing down the economic recovery [58].

In Japan, one notable dynamic has been how COVID-19 has arrested the decade long decline in suicides, and with a total of 21081, in 2020. More people died from suicide in Oct 2020, than from Covid in all of 2020. The increase was especially pronounced among women younger than 30, who need new mental health policies [59] potentially due to the COVID-19 pandemic's disproportionate effect on part-time and travel industry employees. Similar hidden effects have been identified in the UK, where the focus on COVID-19 containment has resulted in widespread disruption in other treatments [60], with as yet untold consequences. Unreliable narratives can fuel inequality and social inequalities need both new narrators and new narratives [61]. Inequality on a regional basis has become topical in the UK, 
with a 'Levelling Up' policy offering a range of benefits linked to greater and fairer personal opportunities, necessary productivity enhancements, and overall growth and development of the economy. The UK Government's central mission is being led by the Levelling-Up Secretary Michael Gove, who is focused on "making opportunity more equal across the country" [62]. Many have felt that COVID-19 has hit those least well off in terms of education with school closures, but the recent Ofsted Annual Report [31] indicates that "nearly all children fell behind at school during devastating lockdowns", with long term consequences unknown.

A direct consequence of inequality is the rise of mental health and increasing stress on health systems and health workers, which necessitates the need for better awareness and focused conversation. While some have commented that the stigma of mental health has been tabled and therefore lessened [64], the WHO have indicated that COVID-19 has adversely disrupted mental health services everywhere [65].

Going forward it is mooted that culture will become more important as ideas taken around the world but it's greatly enhanced in Japan by it being relatively homogeneous, almost 100 percent literacy, .., minimal immigration. Like the UK there is a national health service [66], but the social mores are distinct, with Japan having a unique perspective globally and perhaps a renewed confidence[67]. Notable examples recently highlighted include:

1. Diversity- government goals of filling 30 percent of leadership roles by women by 2020 has failed [68]. Indeed, over a third of the listed major corporations in Japan have no female executives [69]; an on-going issue that Noda-san, Minister in charge of Gender equality feels will improve since "there is data showing companies with higher ratio of female executives perform better."

2. Governance- for an international perspective the Japanese management systems have had numerous high profile examples of questionable corporate governance from Olympus and Toshiba accounting irregularities; general perception of poor shareholder ROE; Mitsubishi Motor Corporation failing to report defects; ..., and poor political and leadership appointments, such as recently where a Japan Cabinet advisor had to resign after only a week when it became clear his position was no longer tenable due to taking COVID-19 subsidies [70] as well as financial irregularities by the leadership of Nihon University [71].

3. SDG's v. ESG-Japan's corporate stewardship framework was intended to follow the UK's FSA, but in detail and execution, it does not come close especially regarding 
engagement between shareholders and corporations, and especially constructive engagement by large shareholders [72]. While relatively poor in corporate governance even amongst its Asian peers, Japan is relatively good on ESG reporting especially regarding climate change [73].

4. Family law- the Japanese law has no provision for shared custody when parents separate. Unofficial data suggests that some 150,000 children are forcibly separated every year. The case of a French father, whose daughter and son were 'kidnapped' was raised at the governmental level when President Macron visited Tokyo for the delayed 2020 Olympics. The French authorities most recently issued an arrest warrant for 'parental kidnapping' [74].

5. Robotics - one notable advantage that Japan can leverage is their leadership in industrial robotics that can be redeployed for people [75]. The acceptance of advanced assistive technologies reflects an open-minded and deep ethnographic approach as public-private, collaborative initiatives to improve ageing, QOL. Understanding local and personal needs is fundamental to the successful adoption of technology. One such example is the Kobe Biomedical Innovation Cluster (KBIC)development, where the Kobe City government is positioning itself at the forefront of making medical and healthcare-related technology accessible to the Japanese people.

What Japan creates for itself as a society can also be leadership in technology governance for other countries by developing these new product technologies for export to other cultures right from the beginning. This includes regulatory systems, architectural programs, and general systems thinking for medical facilities. In this way, a new symbiosis between man and machine, created in Japan, can be deployed globally in a truly local fashion. An aging world is not a burden - it is an opportunity. Japan is writing the first chapter of this story ahead of the rest of the developed world in the most dramatic way [76]. Japan will invent out of national necessity a wave of high-value exports in medical robotics and automation it will need for its own citizens.

One successful initiative reframing healthcare globally is the concept of 'Positive Health' mooted by the Dutch GP, Machteld Huber [77 \& 78]. At its core, Positive Health is "the ability to adapt and to self-manage, in the face of social, physical and emotional challenges." It represents the fundamental shift in healthcare from a treatment mentality to a (proactive) preventative mindset and behaviour. The onus is on the individual to act, but the onus on society to provide the basis for informed choice, and effective communications will be central 
to affecting change. That said, there must be close regulatory governance. For example, a worrying fact associated with the rising trend in mental health apps is the ability for an individuals' emotional data to be hacked [79]. Socially deployed narrative can be an effective catalyst and conduit for all constituencies to embrace new possibilities and create like-minded communities to actualize new possibilities. Such dialogues will need to be multi-disciplinary amongst potential stakeholders, who may have different expectations and/or priorities.

That said openness and coherence will be fundamental to establishing trust and materializing the potential of LifeStyle by Design [80]. There is a tremendous opportunity given the rich stream of inventions demanding careful translation to realise innovation, by creating value. \{In the 2021 Global Innovation Index [81], the UK ranked fourth, after Switzerland, Sweden, and the USA, while Japan ranked 13 overall; 11 on innovation inputs and 14 on innovation outputs. That said, relative to GDP, Japan's performance is above expectations for its level of development $\}$. The imperative is to 'simplify the complex' and offer a clear and coherent purpose through the strategic leadership narrative. Easy to say, and yet seemingly difficult to coherently act on every day, in a practical and useful way, that make true leaders stand out with a stance of 'doing the right things' [82] and not simply only talking about them!

\section{New Ways of Thinking and Communicating}

Such is the nature and rate of change that all institutions, public or private companies, need a strategic leadership narrative that inspires their people and moves them in a consistent and coherent manner. A fundamental requirement will be the need to simplify the complex and envision a destination with purpose. Technology will be the engine of many innovations, just as machines were the growth engines of societal development in the industrial age. While the overarching descriptor is one of change, it should not be considered an era of change but a change to the Sustainable Age. Sustainable strategic leadership narratives will focus on what is important, being in touch with today; engage with truth; with a direction to transform. No small task. But a task that needs to be done urgently as the context for business is being transformed by technology, demographics, global interconnectedness and, more recently, accelerated by the pandemic.

Empowering people demands clear and coherent communications architecture since it is executional excellence that will move people. The communications architecture will reflect the multiple audiences, with multiple perspectives and therefore multiple objectives. Such 
engagement is readily feasible in the 'Mess Age' [83] increasingly dominated by social media and community conversations. The 'Mess Age' is to the Sustainable Age what mass media [84 \& 85] was to the Industrial Age. To accelerate the diffusion of innovation one needs to engage in a way to help shift attitudes as a precursor to change in behavior. Critical therefore not only to have the right content, in context, but to understand how people feel, their emotions, since they help drive future behavior. In truth, the world is already rich with engagement 'in the wild'. The voracity of data empowers readily scalable insights, that objectively ground the new ways of thinking and communicating that are now practical, every day. For any strategy to engage successfully with fast-flow social media, it is essential to understand the context within which such media are relevant to the narratives at hand, and to those who engage with those narratives. The characterisation of engagement with the narrative makes this possible as discussed in the following section.

\section{Narratives that can shape our world}

A core tenet of LifeStyle by Design is to empower the individual to make an informed choice about their personal life options. The approach is bottom-up and personal, readily scaling first at the community level that has seen greater material prominence since the pandemic started. Moreover, as self-medication and healthy lifestyle choices become increasingly important social sharing of new ideas and practices that go viral will have the potential to drive major attitudinal and behavioral shifts that enhance 'healthspan', and the 100-year life [86 \& 87]. For example, mental health is improved by spending time in nature; known as green social prescribing. Recent research shows that more than $90 \%$ of respondents said woodlands were important to them in reducing stress [88].

While the Japanese governments' Society 5.0 view means that science and technology innovation will lead changes that create a new society it does demand that any communications must be inclusive and understood and embraced by multiple constituencies. The diffusion of new ideas is greatly enhanced by the almost ubiquitous participation in social media. Indeed, narratives and social media are integral parts of today's connected world. Critically, trust is paramount as it is amplified in a social setting and more than ever people find trusted voices in their networks; people trust people! The ubiquity of the internet and mobility have enhanced the importance of social media (first coined in 1994 by the founders of Significance Systems, John Ricketts and Darrell Berry [89]). Naturally the increasingly popular Living Lab is constrained physically, the holistic and objective investigation of 
stories taking place in our ever-increasing online world, transforms traditional social survey methodology, with a detailed and objective perspective of affective impact.

The analysis of literally thousands of online conversations provides an authentic understanding of how social groups react at an emotional level, at any moment in time. earth.ai can sense and quantify over 400 named emotional states in response to any story. It uniquely helps to understand what is significant to people in real-time -- not what commentators, companies, or politicians think is important. Indeed, since emotions precede actions / behaviour understanding how people feel is critical for better decisions, by business or policymakers. This approach is consistent with actor-network theory (ANT), which posits that everything in the natural and social worlds exists in a dynamic network of relationships that is constantly changing. Therefore, ideas and process are seen as just as important in creating the social circumstances, as human beings themselves. The approach is described as a material- semiotic methodology which maps relationships that are material (between things) and semiotic (between concepts), simultaneously [90]. (Latour's seminal philosophy reassessing modernity based on the contrast of nature and society was acknowledged by the 2021 Kyoto Prize [91], Laureate in Arts and Philosophy).

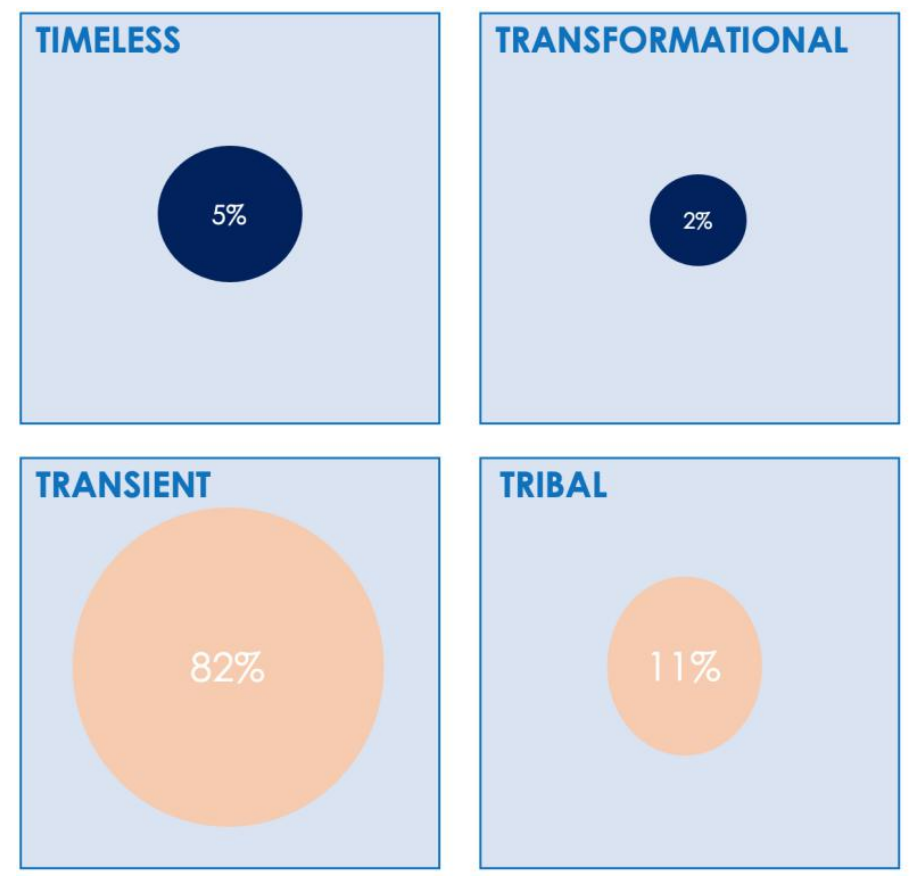

Figure 3: Narrative classification and relative importance (frequency; \%)

This state-of-the-art communication science that looks at all open, online sources, driven by AI, can identify Timeless and Transformational narratives that have utility and can effect change (Figure 3), and create sustainable value. LifeStyle by Design proposes to leverage social media to ensure the effective and efficient delivery of the appropriate narratives, in 
context, to different constituencies. It is anticipated that this will help create Community Value, which is consistent with Mulgen [92] urging social scientists to envision and craft a more sustainable path ahead. Since June 2019, we have consistently explored lifestyle narratives in the UK and Japan, to benchmark and draw novel yet scalable implications for policymakers and public and private institutions, alike.

Measuring and interpreting social and linguistic signals by accessing openly available online content is naturally more directly reflective of human behaviour, than traditional qualitative or quantitative survey methodologies. Critically, they also provide a coherent diagnostic base to understand, exploit, and change behaviour. Significance Systems measure and characterize long-term engagement for narratives (Figure 3). Naturally, a priori distinctive narratives behave in discrete ways and vary in their value and utility. Most internet exchanges are whitenoise and thus most narratives, unless harnessed, are transient (82 percent); having low engagement. Transformative narratives, in general, reflect only 2 percent, while those that are transformative account for 5 percent. Tribal narratives account for some 11 percent, in general, but while characterised by intense debate it rarely has any impact. If one considers the narratives of the top 100 brands/companies, then their effective communications strategies are focused one sees timeless engagement representing at least 90 percent of the narratives [93].

Since people find trusted voices in their networks, this type of analysis enables one to 'engage with engagement' and thus be part of the on-going story rather than to try to dominate it from outside, which has been the traditional mass communication norm of intrusion. In "Narrative Economics", Shiller [94] goes much broader and deeper, demonstrating how the stories we tell ourselves about the world drive our behaviour — and thus the world itself if enough people buy into them. As such, the methodology is breaking the approach of traditional consumer research methodologies providing more relevant, timely, and actionable insights. LifeStyle by Design needs to align with and create popular stories that go viral and can affect individual and collective, community behaviour. 


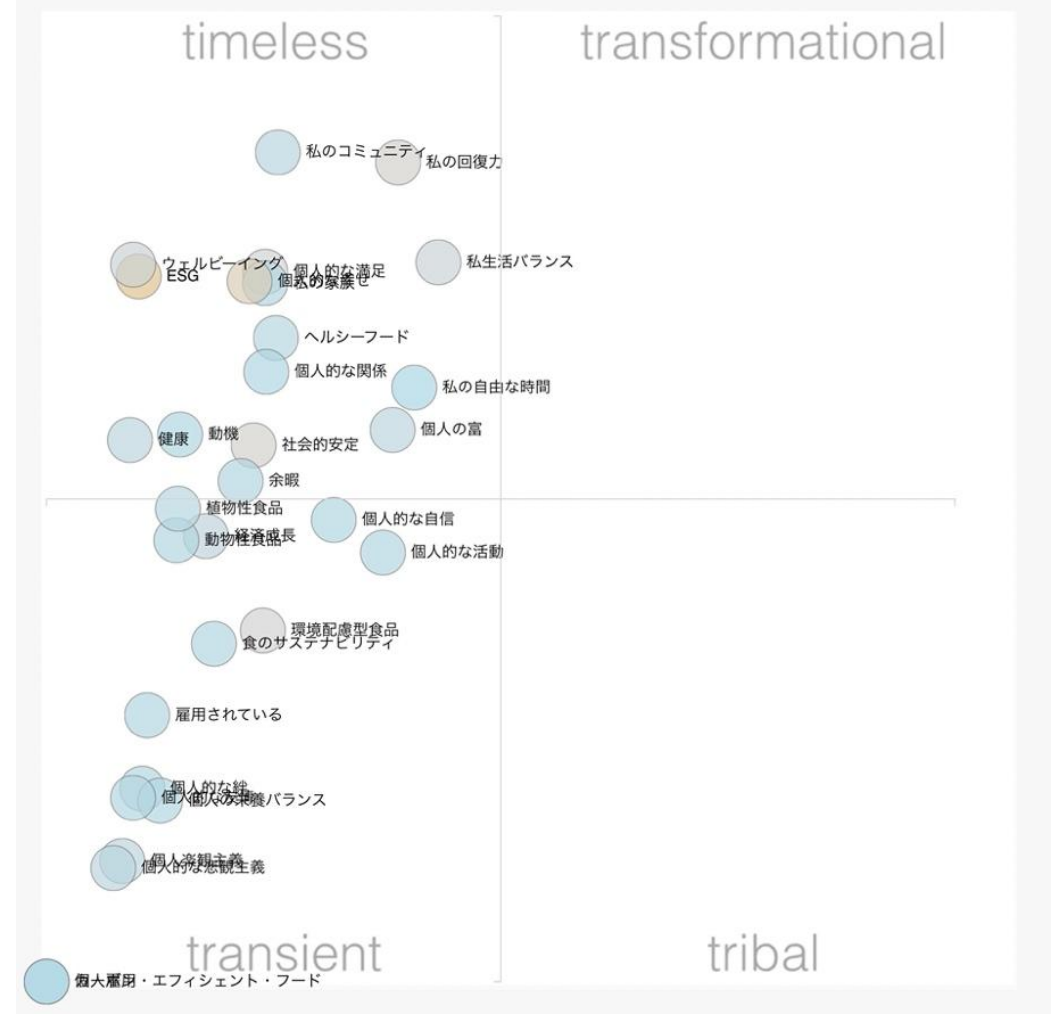

Figure 4a: Landscape of Narratives in Japan

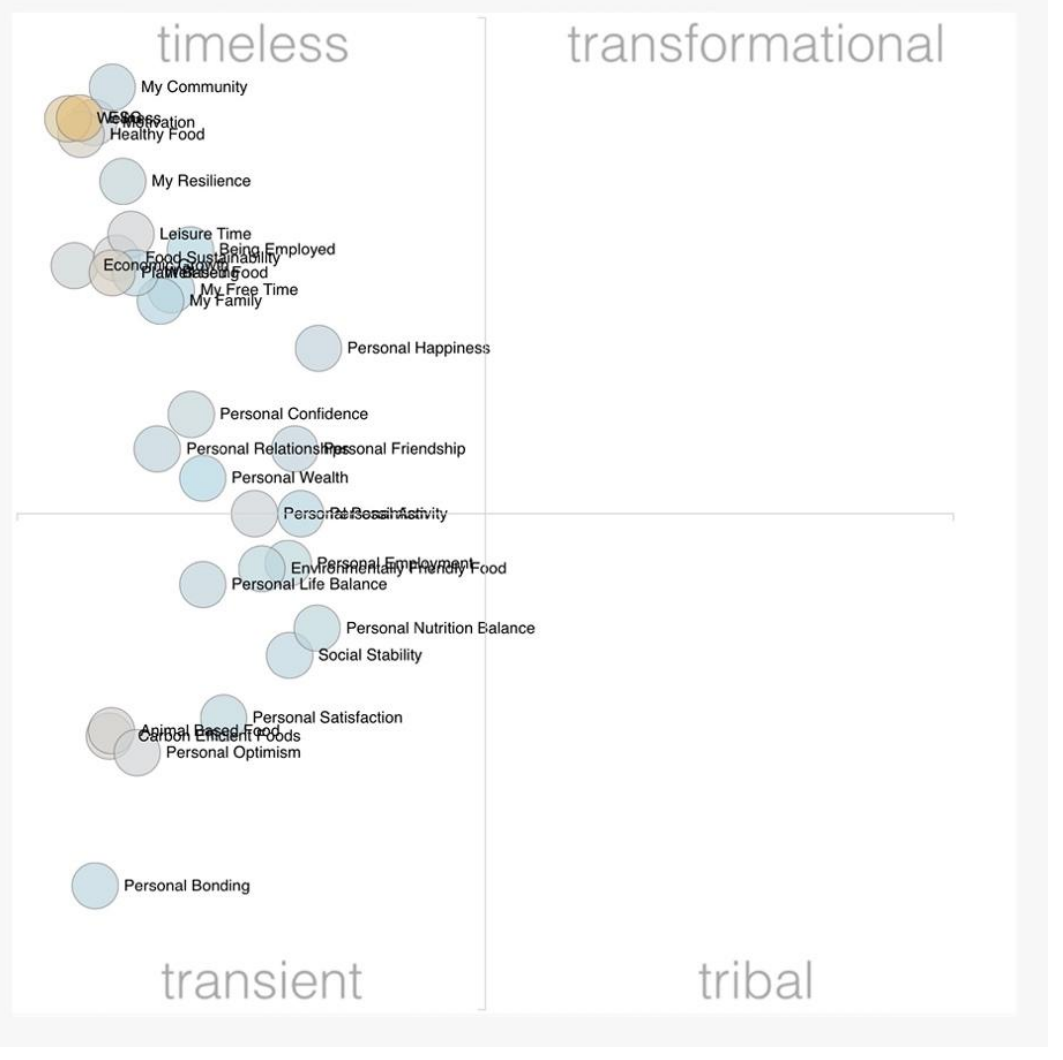

Figure 4b: Landscape of Narratives in the UK (December 2021) 
The LifeStyle by Design, Virtual Living Lab was established in June 2019 [93]. The narratives used in this analysis (Table 1; Figure 4a \& b) were identified by subjective PreSearch of different current publishing channels broadly related to health and wellness. This was felt most efficient in establishing a broad but somewhat focused benchmark which would overcome the transient nature of most narratives.

Table 1: Narratives for comparison and benchmarking

\begin{tabular}{|c|c|c|c|}
\hline English (UK) & Japanese (Japan) & English (UK) & Japanese (Japan) \\
Well-being & ウエルビーイング & motivation & 動機 \\
wellness & 健康 & my community & 私のコミニニティ \\
personal happiness & 個人的な幸せ & personal bonding & 個人的な絆 \\
personal satisfaction & 個人的な満足 & being employed & 雇用されている \\
leisure time & 余暇 & personal wealth & 個人の富 \\
personal employment & 個人雇用 & personal relationships & 個人的な関係 \\
personal life balance & 私生活バランス & my resilience & 私の回復力 \\
personal friendship & 個人的な友情 & personal confidence & 個人的な自信 \\
my family & 私の家族 & personal optimism & 個人楽観主義 \\
personal nutrition balance & 個人の栄養バランス & personal pessimism & 個人的な悲観主義 \\
personal activity & 個人的な活動 & social stability & 社会的安定 \\
my free time & 私の自由な時間 & economic growth & 経済成長 \\
\hline
\end{tabular}

The analyses in this paper incorporate findings of the different waves (Table 2) through to December 2021 (BC and DC[12]). To develop the narrative Landscape illustrated in Figures $4 a \& b$, we look at all online sources, up to the date of the research wave. There is no time window. So, depending on the specific narrative, which self-organises, it could be dominated by recent content ... or not.

The research for each wave, analyses data from the UK and Japan, separately to facilitate comparison. Recognizing that social sharing is more authentic, and trustable than traditional forms of mass communications it is thus now practical, with data-based, real-time, communications insight*, to;

- objectively explore these narratives to understand the drivers and dynamics of changing behavior and consensus;

- probe what people value and feel are more important; 
- establish how new solutions can be effectively introduced to create new and better behaviours

Table 2: Lifestyleby Design Research Waves (2019-2021)

Wave 1(W1): June 2019

Wave 2: December 2019

Wave 3: April 2020

Wave 4: June 2020

Wave 5: December 2020

Wave 6: June 2021

Wave 7: August 2021

Wave 8: December 2021

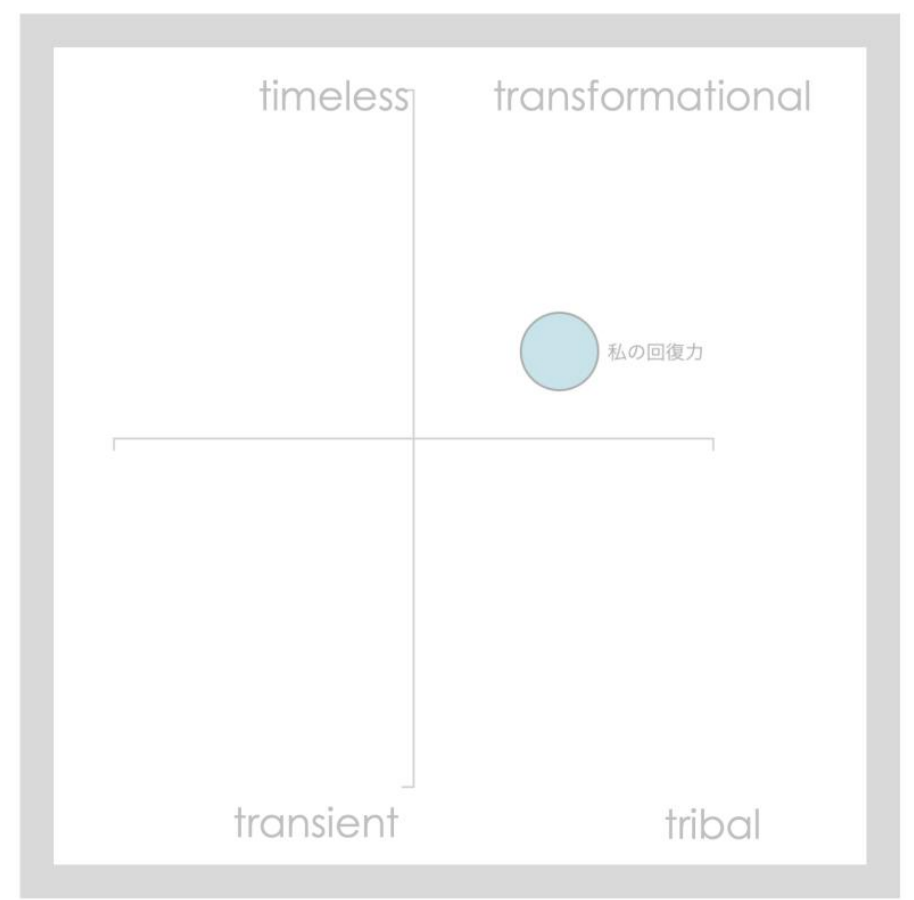

Figure 5: Narrative Classification: My Resilience [私の回復力](Japan, Wave 1; June 2019)

A small number of narratives are timeless (Figure 4) and fewer still transformational. The timeless narratives are characterised by deep engagement in the long term, and usually driven by a small number of key players who are perceived to be experts and or authorities. These timeless narratives make good choices for communicating new ideas. They are of high value but difficult to own, so the imperative is that the messaging is focused. From a point of view of the narrative raising societal issues they are expected to persist and or grow. The transformational narratives are characterised by intensely engaged experiences with strong 
timeless themes. These narratives are fast-changing, yet potentially result in lasting transformation of the world. They provide a volatile environment for the positioning themes for communications: strong opportunity if there is positive alignment, or a great threat if an opposed issue. My Resilience (私の回復力) is such a transformational narrative in Japan, in June 2019 Figures(4 \& 5).

\section{Content Efficiency}

Weak

Average

Strong

Figure 6: Narrative Content Efficiency

A measure of the extent to which the existing narrative content is significant is represented by content efficiency (Figure 6). High content efficiency indicates that much of the existing content within a narrative is significant, in cost trust a low score means that there is a gap between the needs of the narrative and the existing content. In Wave 1 (Figure 4) Wellness in Japan (健康) had the highest content efficiency.

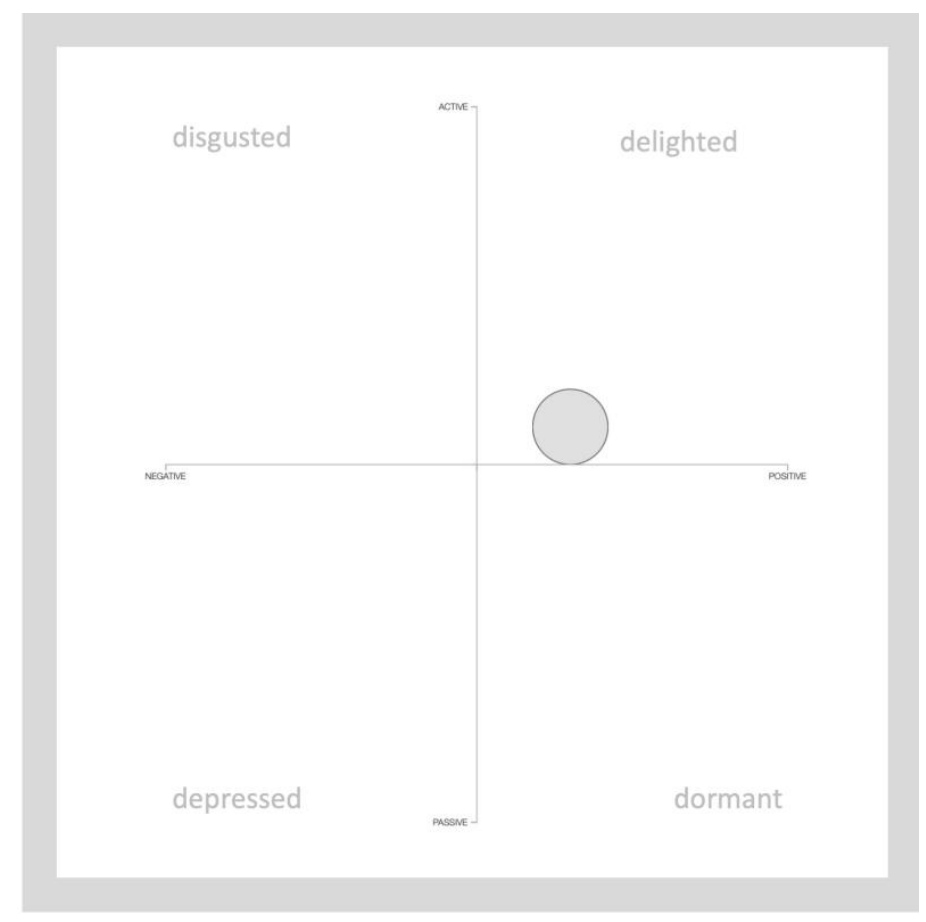

Figure 7: Affect Orientation: My Resilience [私の回復力](Japan, Wave 1; June 2019)

A critical element of the analysis is to understand what emotional response is stimulated by the narrative. This is referred to as the affect orientation; it is positive or negative and active or passive. Most narratives create no emotional response; they are neutral. The Affect Orientation of My Resilience (私の回復力) in Figure 7 is characterised by projecting a sense of delight by being active and positive. Furthermore, it is important to understand what the 
most powerful content within a narrative is. This assist in the development of the communication strategy for both content and curation. In this context the content power is a measure of the power of an individual piece of content to capture and drive engagements with the narratives core themes. This measure is one of influence and is independent of the media volume. In the case of My Resilience (私の回復力) in Figure 8 it is Business Insider and the Nikkei that provide the most powerful content.

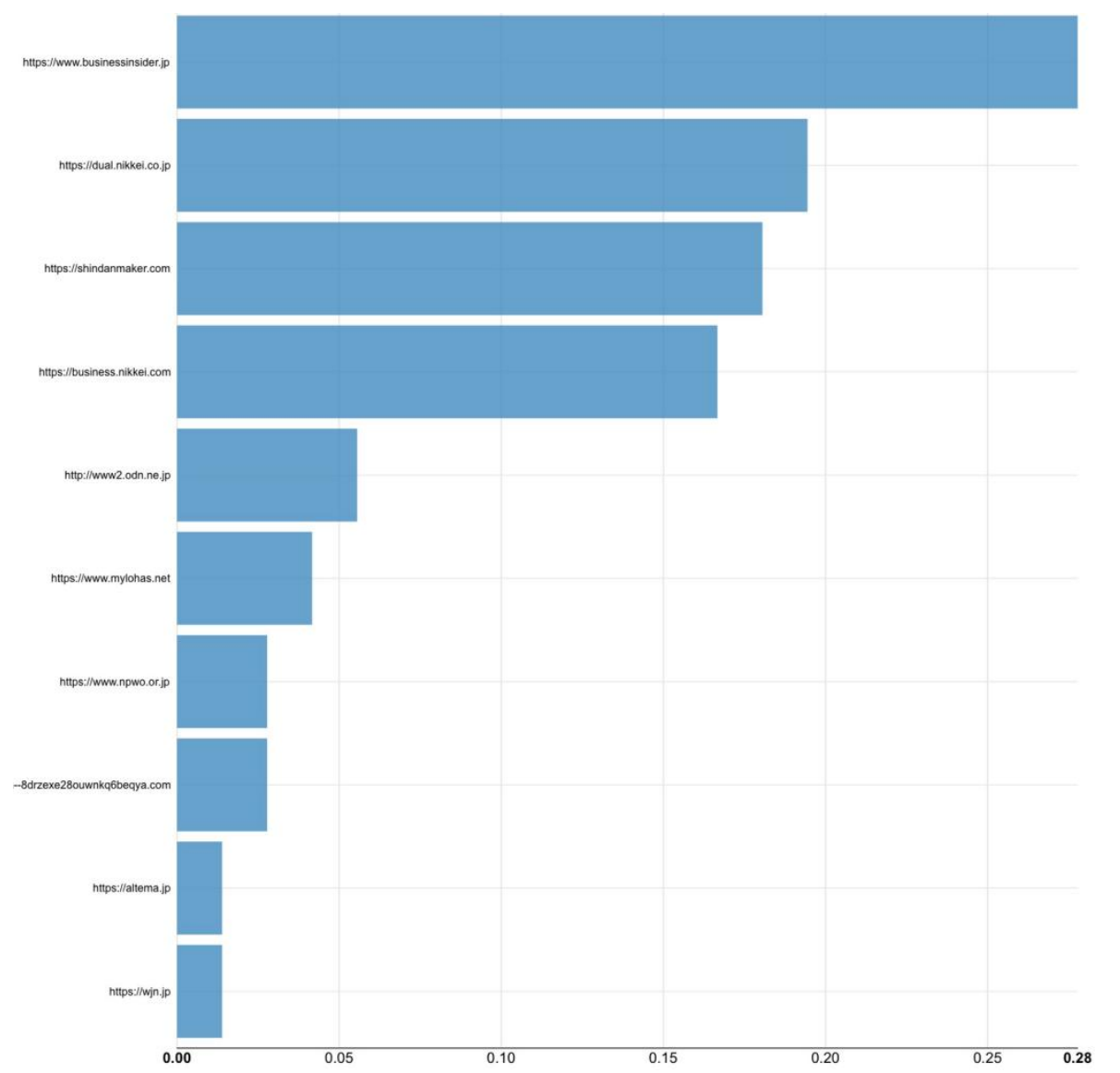

Figure 8: Content Power: My Resilience [私の回復力](Japan, Wave 1; June 2019)

Since our analysis focuses on what people think is important and act on, understanding the influence of emotion greatly enhances the ability to predict future behaviour. Research of emotions [95] see them as 'episodes' a response to external stimulus. The International Handbook of Emotions in Education [96] provides the relationships between specific factors and subsystems. They identify five principal ways in which emotion influences action. The primary functions are in relation to monitoring, support meaning, and communication. It is widely considered that there are more than 30,000 emotions one can experience. The Universe of Emotions app [97] utilizers some 2000 different emotions with the purpose of helping the user improved their emotional intelligence (EQ), by building emotional awareness 
and understanding of their impact on others. Naturally emotions are at the hearts of wellbeing, health, and performance and thus implicitly an important element, of Lifestyleby Design.

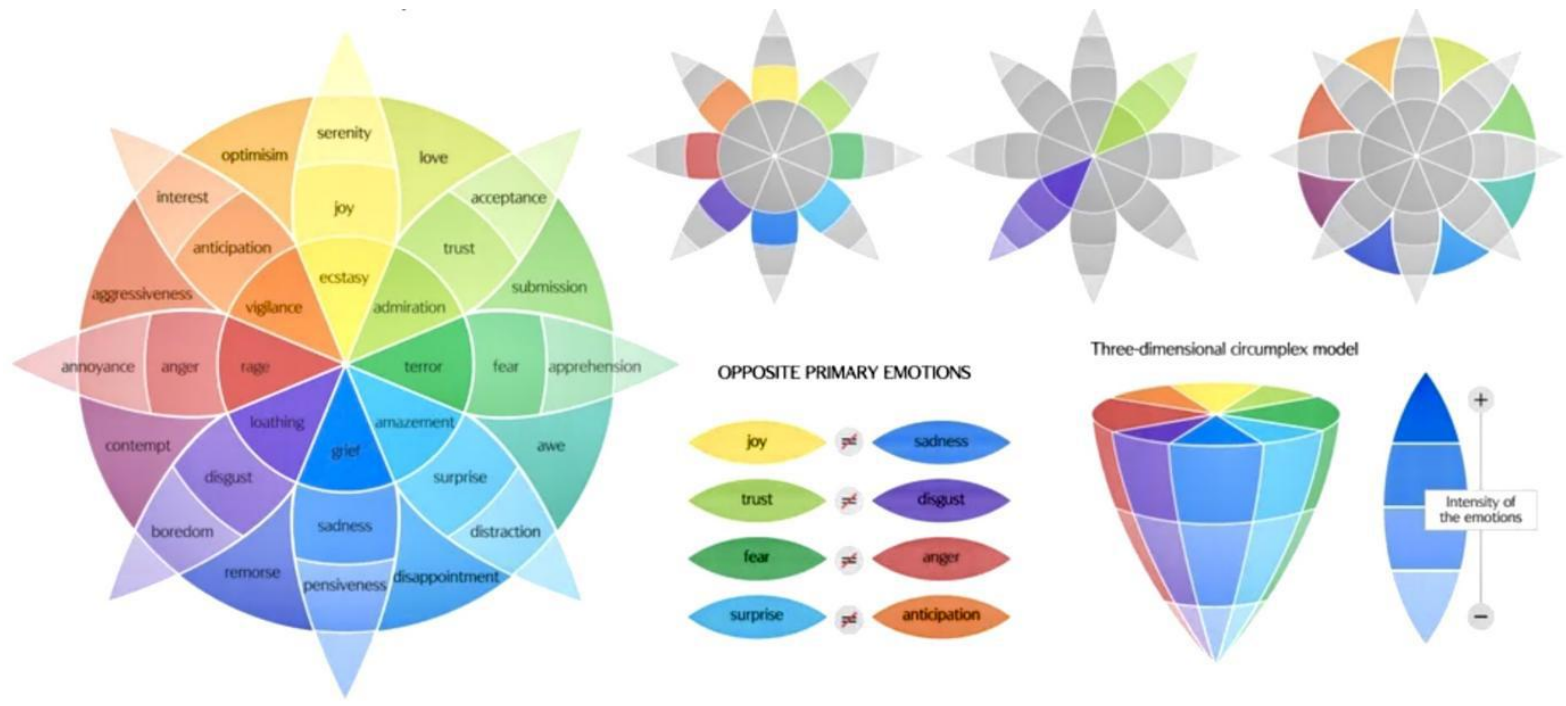

Figure 9:. Plutchik's circumflex model of Emotional Feelings

To be able to navigate all these emotions, the American psychologist Plutchik recognised a hierarchy where by 8 primary emotions provide the foundations for all the other emotions. these are: joy and sadness; fear and anger; surprise and anticipation; and trust and disgust. An ability to identify these primary emotions is critical especially at times of deep feeling when often people react on impulse rather than by rational objective. Plutchik's critical contribution is his 'wheel of emotions' (Figure 9), where the eight primary emotions are grouped into their opposites, with the basis for his emotions theory founded on 10 postulates [98], which pragmatically enables the wheel to simplify the complex.

It is important to note that the methodology and process outlined here can leverage large amounts of online content and behaviour. These rapid, large-scale surveys allow for resilient longitudinal analysis together with flexible and effectively real time, deep dives as issues emerge in the real world. As such they are an ideal complement to the small scale, small sample prototyping often associated with living labs and psychological studies. Indeed, there is promise in the application of this process to provide a big data counterbalance to the many empirical studies and conclusions based upon small samples and go some way in generating greater resilience and reproducibility across several fields in a manner similar to the hard sciences' access to large numbers and a firmer statistical footing. 


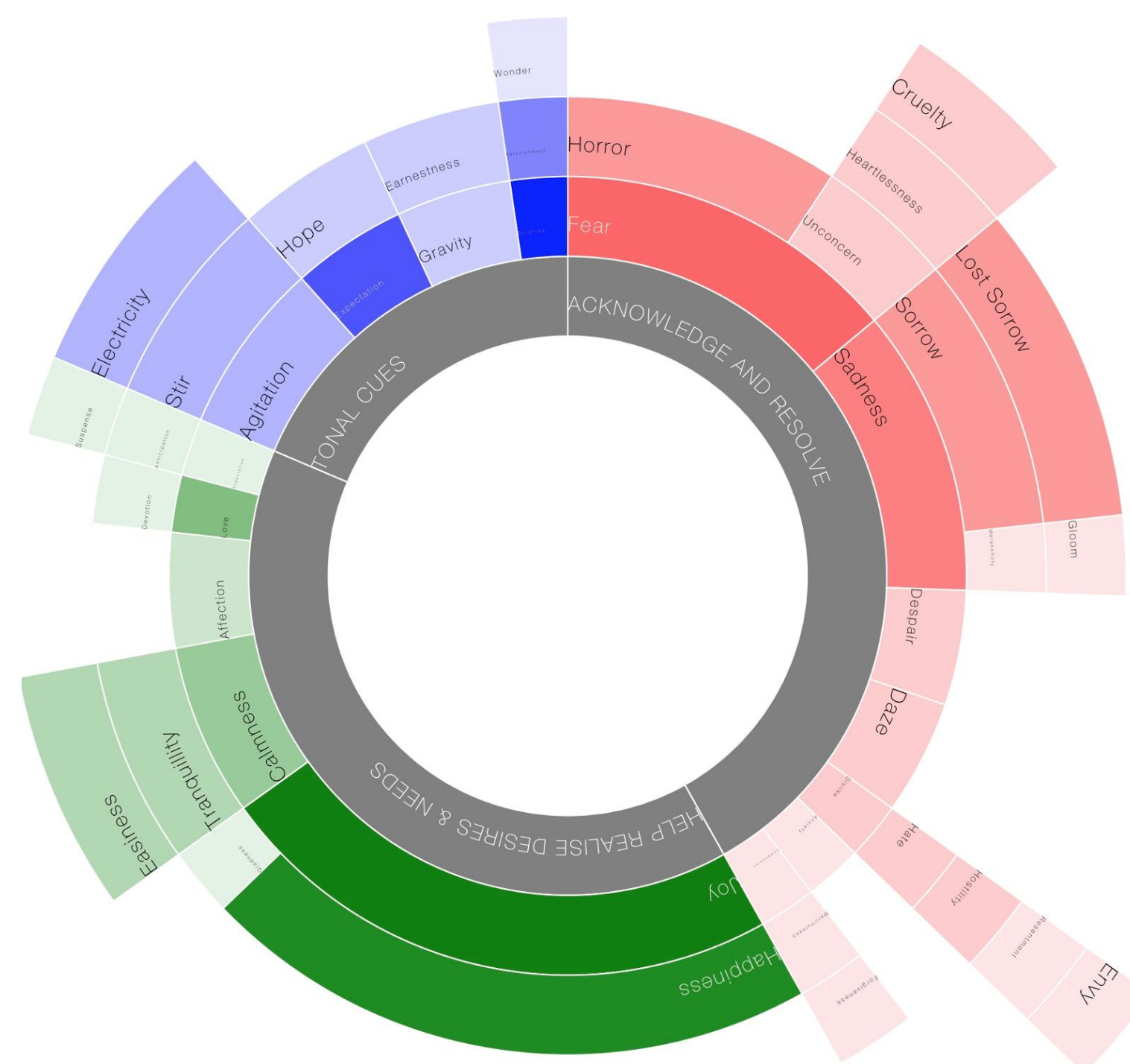

Figure 10: Emotional Response: My Resilience [私の回復力](Japan, Wave 1; June 2019)

As indicated above the affect, emotional response to a narrative is important since it provides an indication of the emotional tone of the significant content. With an understanding of the emotional drivers, one can better understand and respond more relevantly and credibly with an understanding of the emotional impact of the narrative. In this chart (Figure 10), positive emotions are highlighted in green whereas negative emotions are in red. The intensity of the colour indicates the intensity of a specific emotion. If there is a clear tonality to the emotions expressed such as apprehension or expectation, these are shown in purple. The width of each arc, in the emotional wheel, reflects the degree to which the specific emotion contributes to the overall emotional response. Broad emotions, such as love and fear, are closer to the centre of the wheel. The most subtle emotions, which contributes to the broad emotions are represented in the concentric rings that go further out. Moving out from the centre, each emotional ring shows a further level of granulation. 
My Resilience (Figure 10) has both positive and negative emotions expressed a key segment is that happiness is creating a sense of joy and that there are strong tonal clear cues that set the expectations of hope to overcome existing difficulties. On the negative side there is a sense of horror and sorrow that manifests itself in creating fear and sadness for some there is a sense of envy, which can drive resentment hostility and even hate. For the negative elements of any narrative, it's important to acknowledge and try to address and resolve them. Regarding the positive emotions individuals still need help to realise that desires and needs, which can convey a sense of credibility through understanding.

Understanding of the media which most effectively drives engagements enables the development of focused, cost-effective media strategies, particularly strengthening the relationships and presence with emergent digital media channels. The media power index ranks media voices according to their power to influence and lead debate and the perception within the narrative. It is not a volume metric measure. Often, the most popular media, are not the ones with the strongest impact on topical engagement.

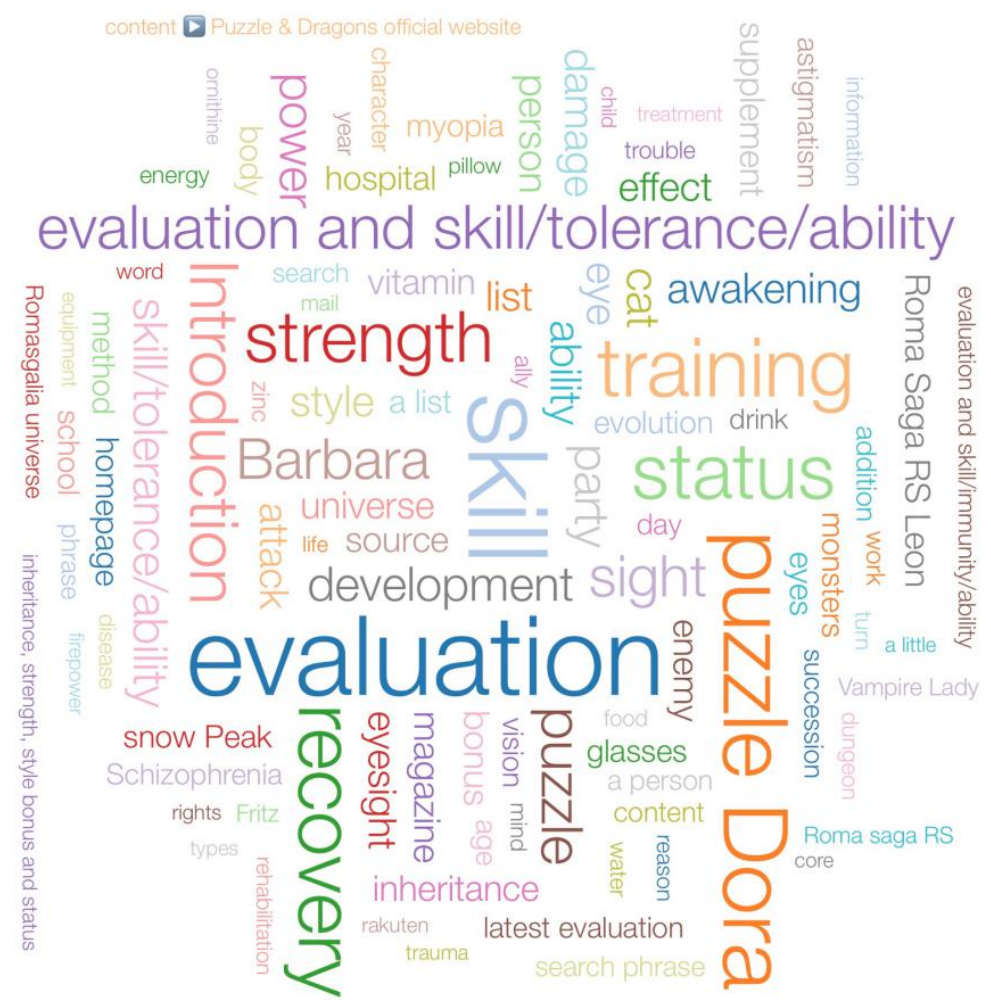

Figure 11: Key Topics within a narrative: My Resilience [私の回復力](Japan, Wave 1; June 2019)

The analysis can also provide a visual exploration of the narrative (Figure 11). The images that amplify the power of a narrative can be readily assessed. In the same way, one can look at the relative importance off they topical drivers, of engagement. If one is to speak with a single 
and unique voice it is important to be aware of the existing messaging since the effectiveness and efficiency can be enhanced materially by 'engaging with engagement'.

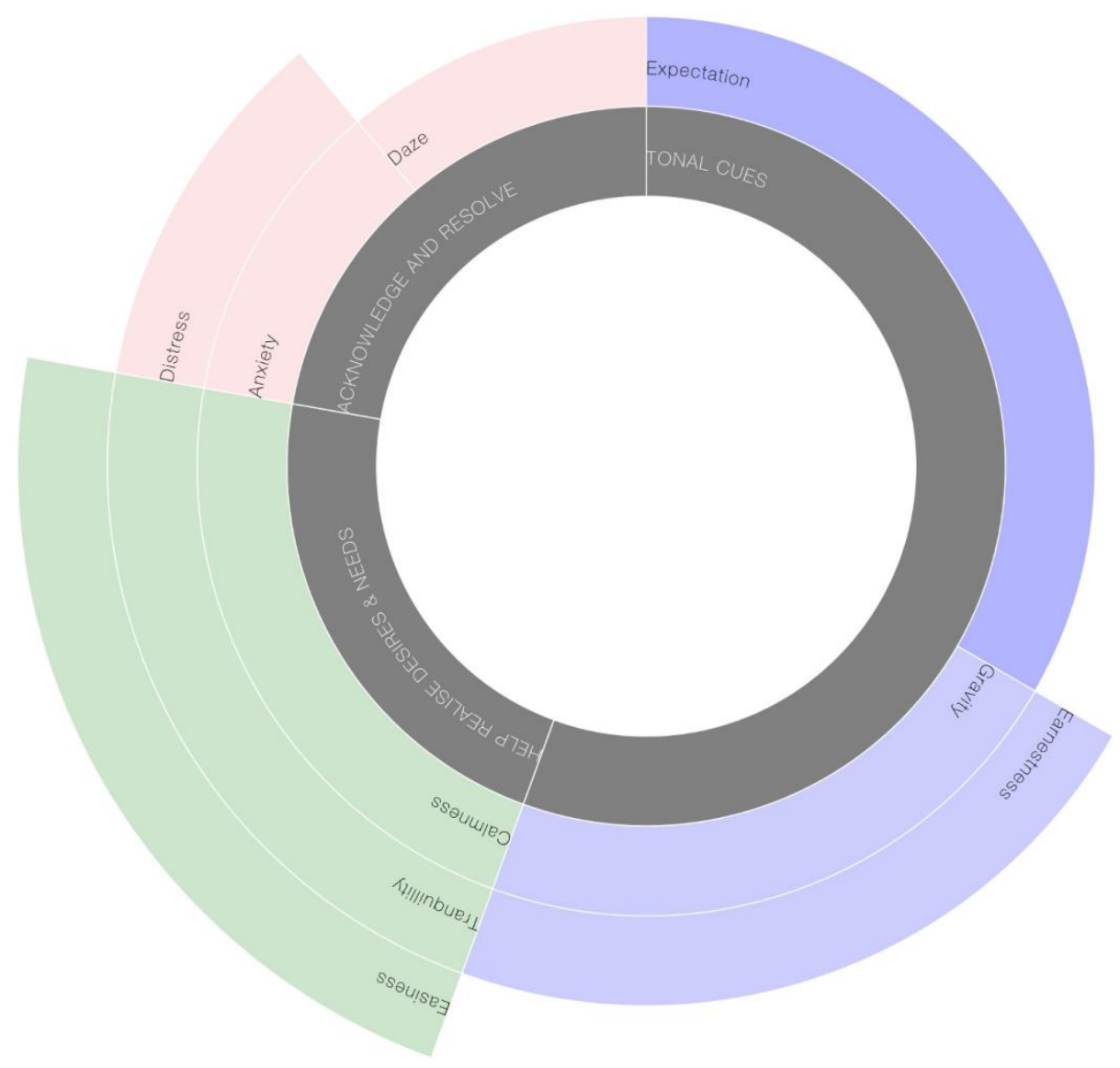

Figure 12: Emotional Response: My Resilience [私の回復力](Japan, Wave 4; June 2020)

In future waves, as the world was affected by covid-19 My Resilience became a transient narrative with the narrative not having a clear emotion response and the affect orientation becoming more negative and passive. For example, the key topics within the My Resilience narrative in Japan in June 2020 were only 'world' and 'spread'. At that time, during the national emergency the key emotions (Figure 12) reflected a sense of expectations and acceptance of the gravity of the situation. One year further on, in June 2021 with covid-19 still creating severe constraints in daily life, the affect orientation had become positive and active, but the emotional response conveyed a sense of stoicism, despite feeling dazed and that the country would come through (Figure 13). With the country remaining under prefectural restrictions the overall mood was more depressed with a stronger negative and passive affect orientation (Figure 14) as another year of annual vacations were missed and the pressure remained with the unknown. 


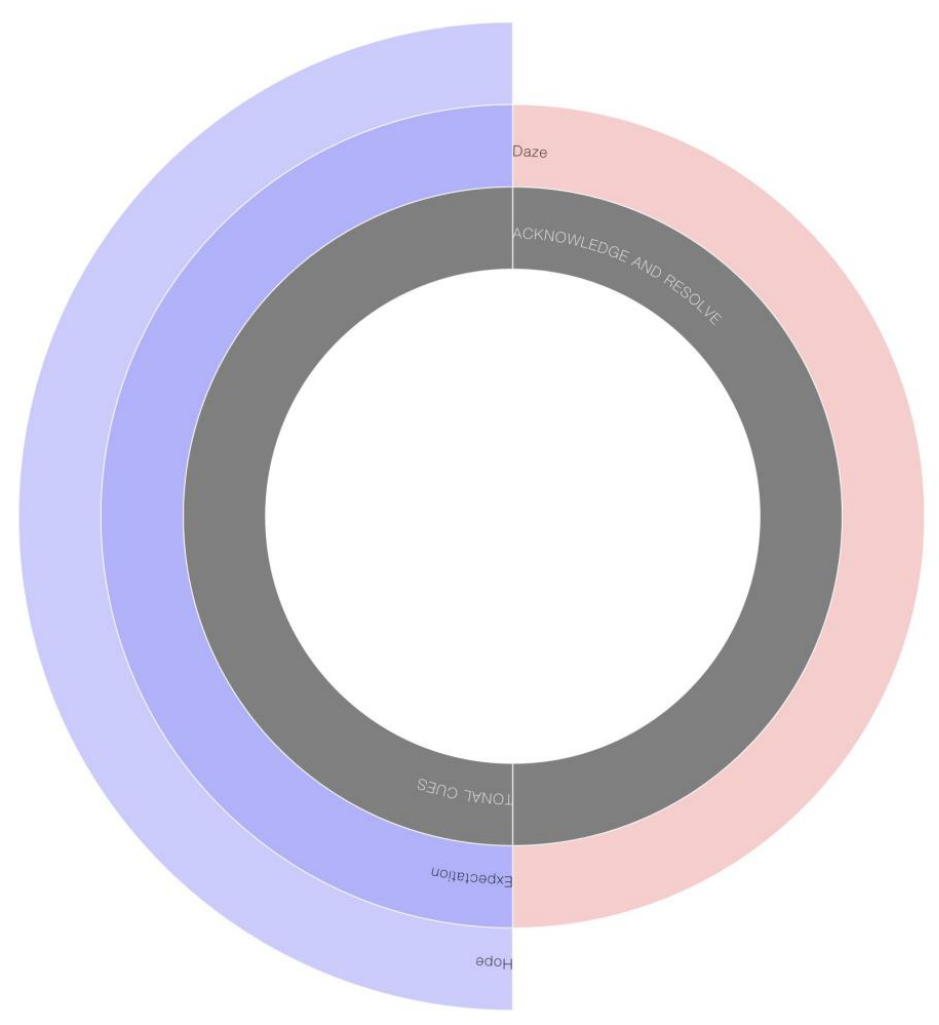

Figure 13: Emotional Response: My Resilience [私の回復力](Japan, Wave 6; June 2021)

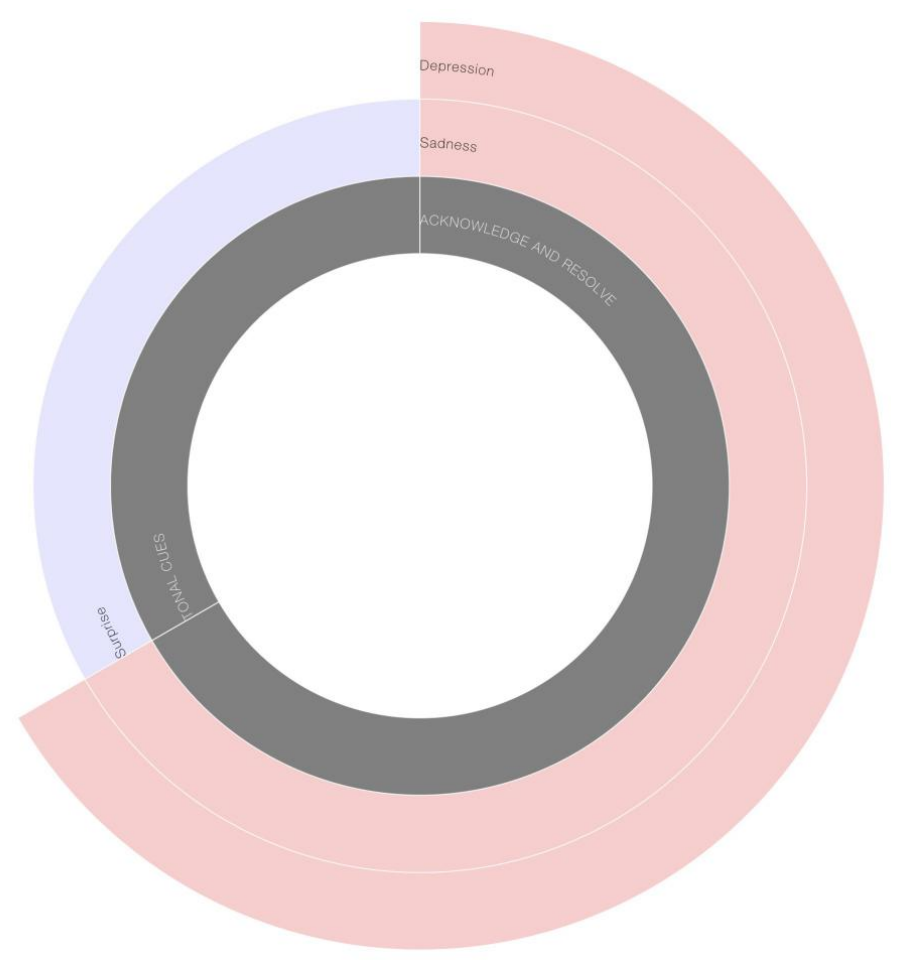

Figure 14: Emotional Response: My Resilience [私の回復力](Japan, Wave 7; August 2021)

However, by the time of the latest wave (8; Table 2, December 2021), the Japan situation was quite remarkable with a relatively low death rate and incidence, despite the super-aging 
society. The emotional response to My Resilience was significantly more positive (Figure 15), even compared to August 2021 (Figure 14), such had been the change in outlook and sentiment. The narrative returned to be Timeless, with improved content efficiency within the narrative. Some commentators suggested it was due to genetics [99], but others feel a number of contributing social factors, despite there being no lockdown as in the UK, including basic hygiene; almost complete but voluntary wearing of face masks, as well as a thorough, if late, vaccination take-up (77 percent), strict border controls and social distancing.

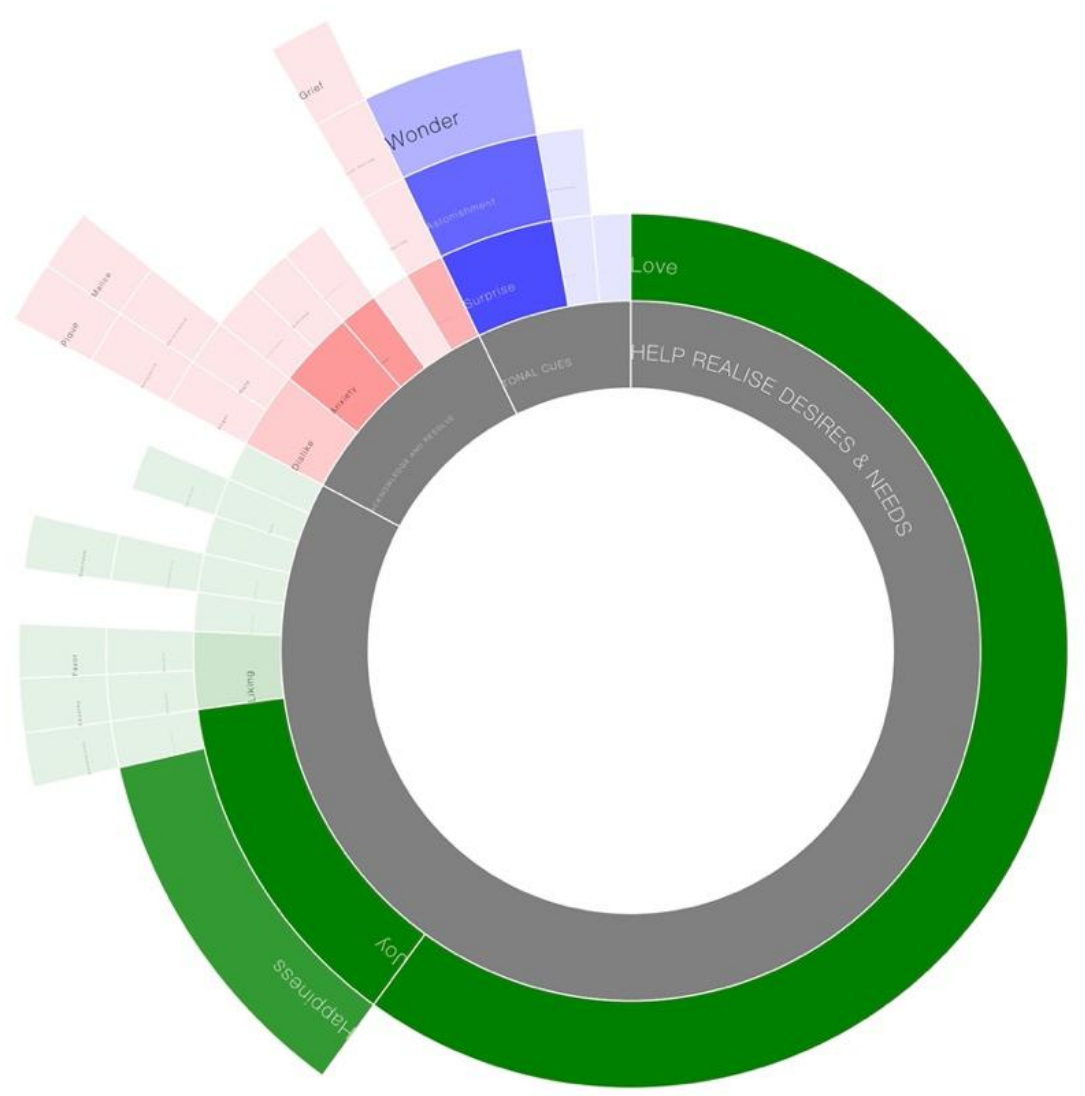

Figure 15: Emotional Response: My Resilience [私の回復力](Japan, Wave 8; December 2021)

In the UK, the situation was quite different with My Resilience remaining timeless (Figure 16), throughout the period June 2019 to December 2021; waves 1 to 8 (Table 2). That said, while the categorisation was constant the influential topics and the emotions associated with the narrative varied appreciatively. A fact that could provide timely input for communications to ensure their relevancy and credibility. Something, that, was not always the case during the national lockdown when messages were often changed, and frequently viewed as contradictory, which added to the stress and despair. 


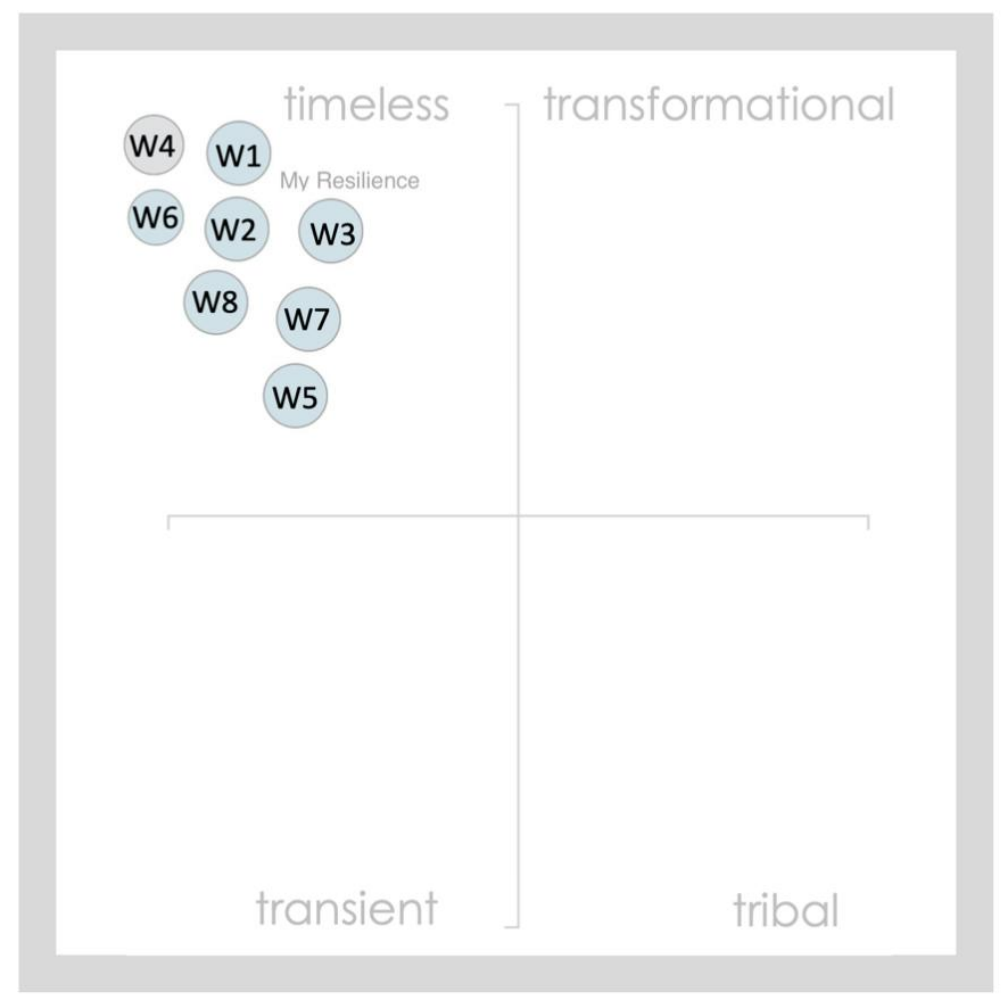

Figure 16: Categorization: My Resilience in the UK June 2019 wave1- December2021 wave8

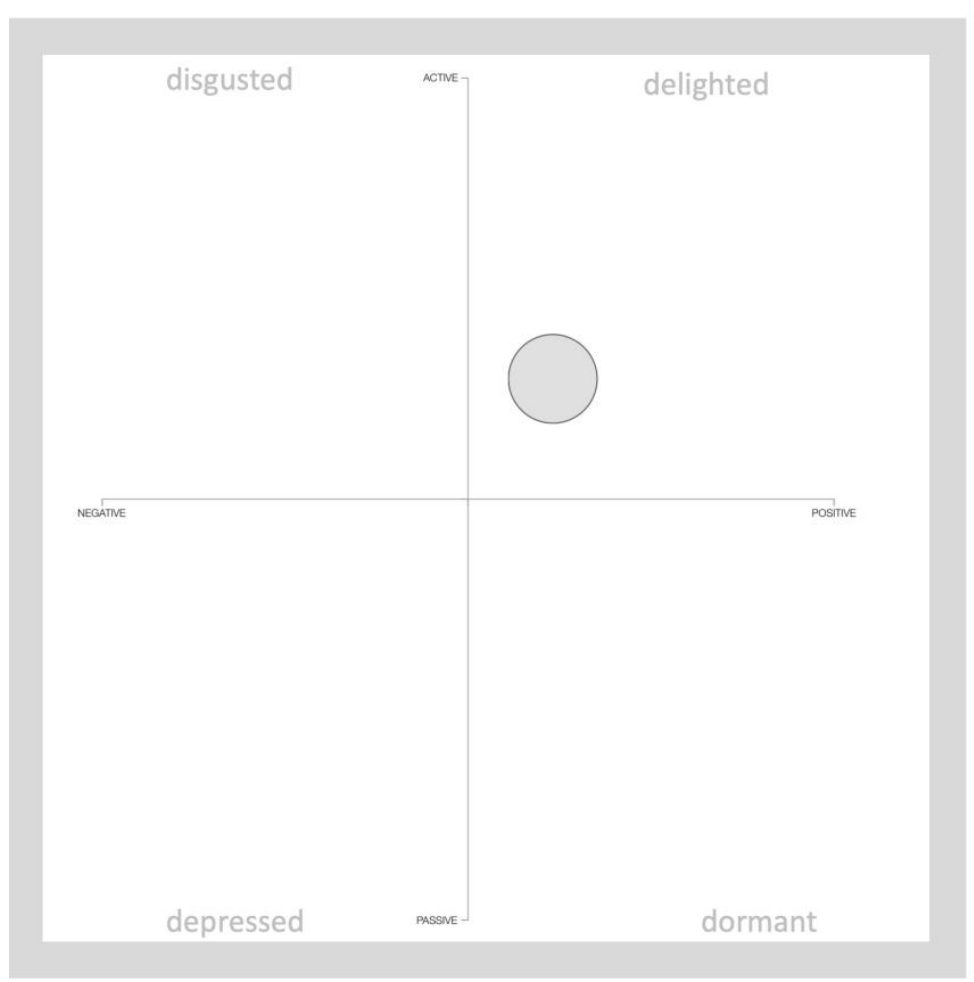

Figure 17: Affect Orientation: My Resilience in the UK, June 2019 


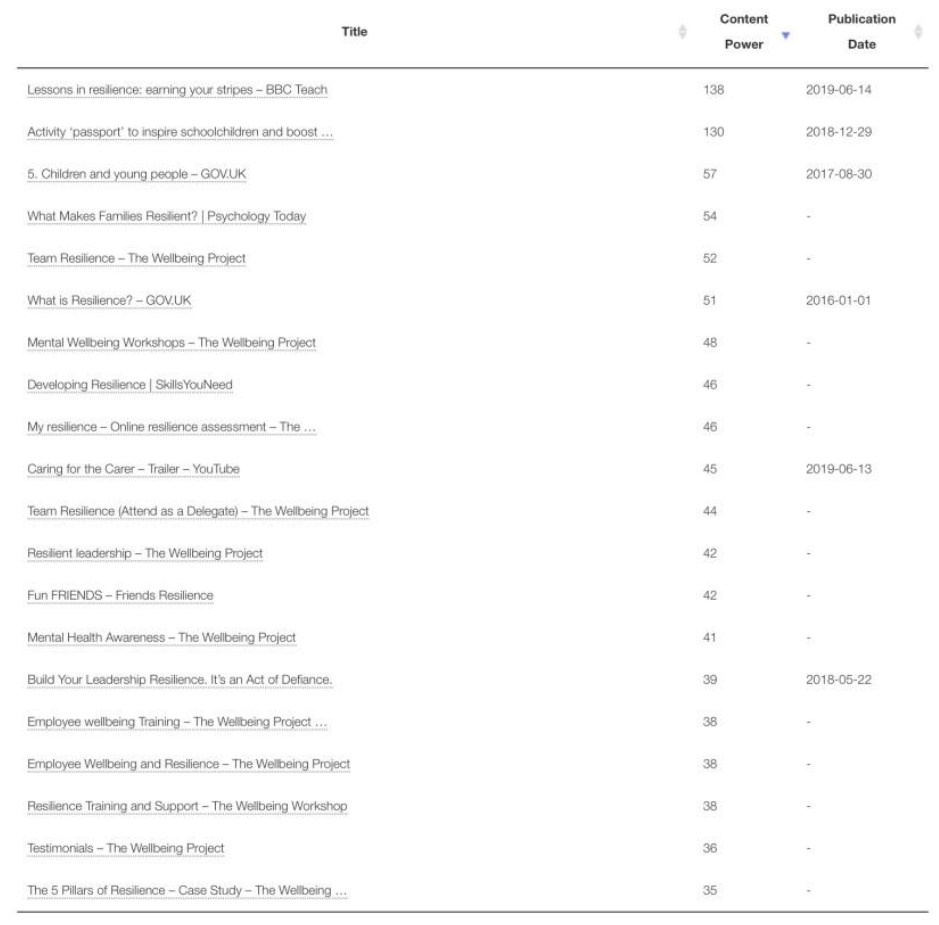

Figure 18: Content Power, in the UK, June 2019

In the first wave the affect orientation of My Resilience, (Figure 17), was active and positive, with the most influential content being lessons in resilience, coming to a large extent (Figure 18 ) from the BBC, GOV.UK and The WellBeing Project. Emotionally, My Resilience back in June 2019 was largely characterised by a mix of positive and negative emotions (Figure 19), with some element of surprise and anticipation. It was an unusual period in a country characterised by future volatility, but personally supported by friends and community (Figure 20), because of the ongoing Brexit debate. After the 2019 election in early December, the Brexit debate had clear resolution and happiness, led to much more seasonal joy, to provide an emotional release (Figure 21). 


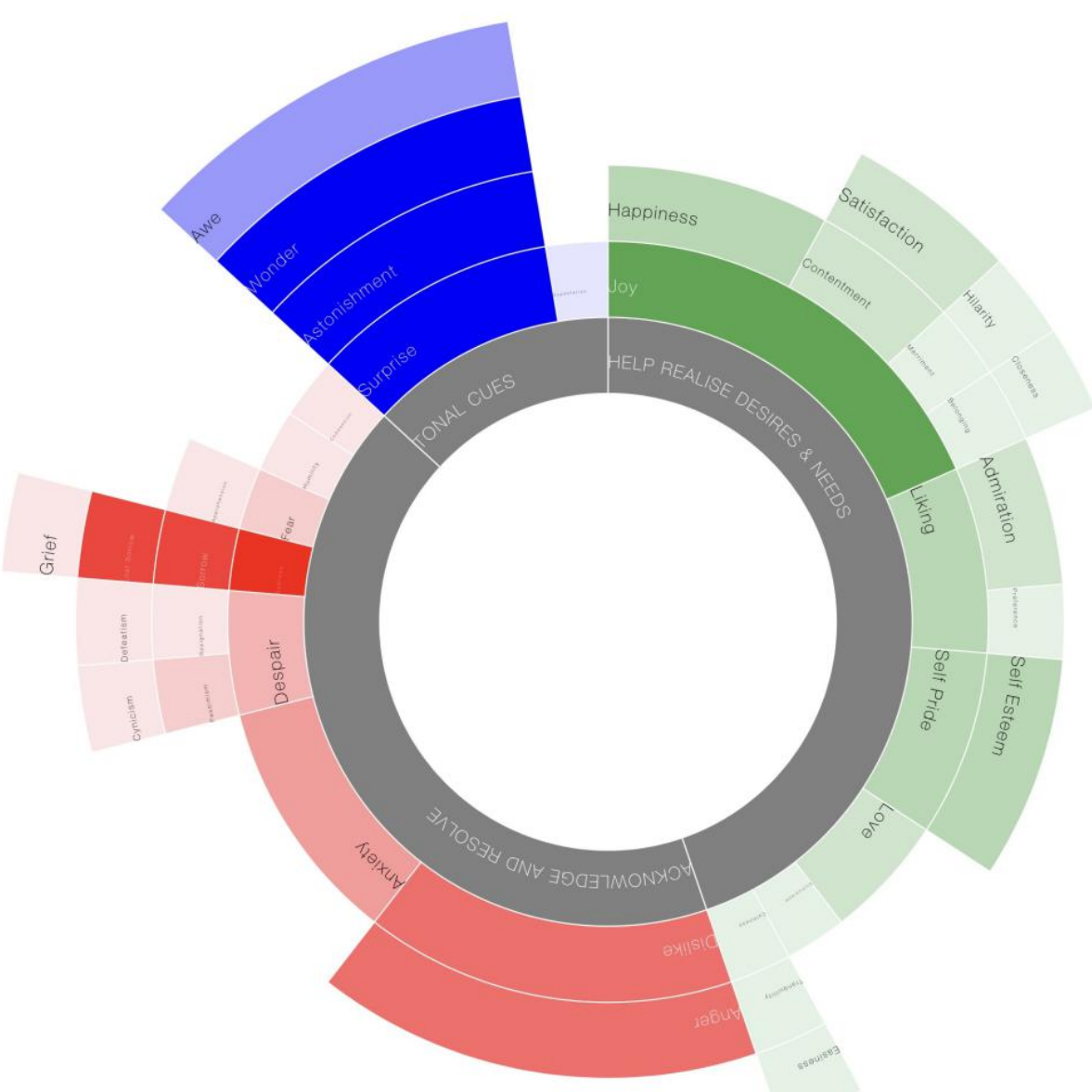

Figure 19: Emotional Response: My Resilience in the UK, June 2019

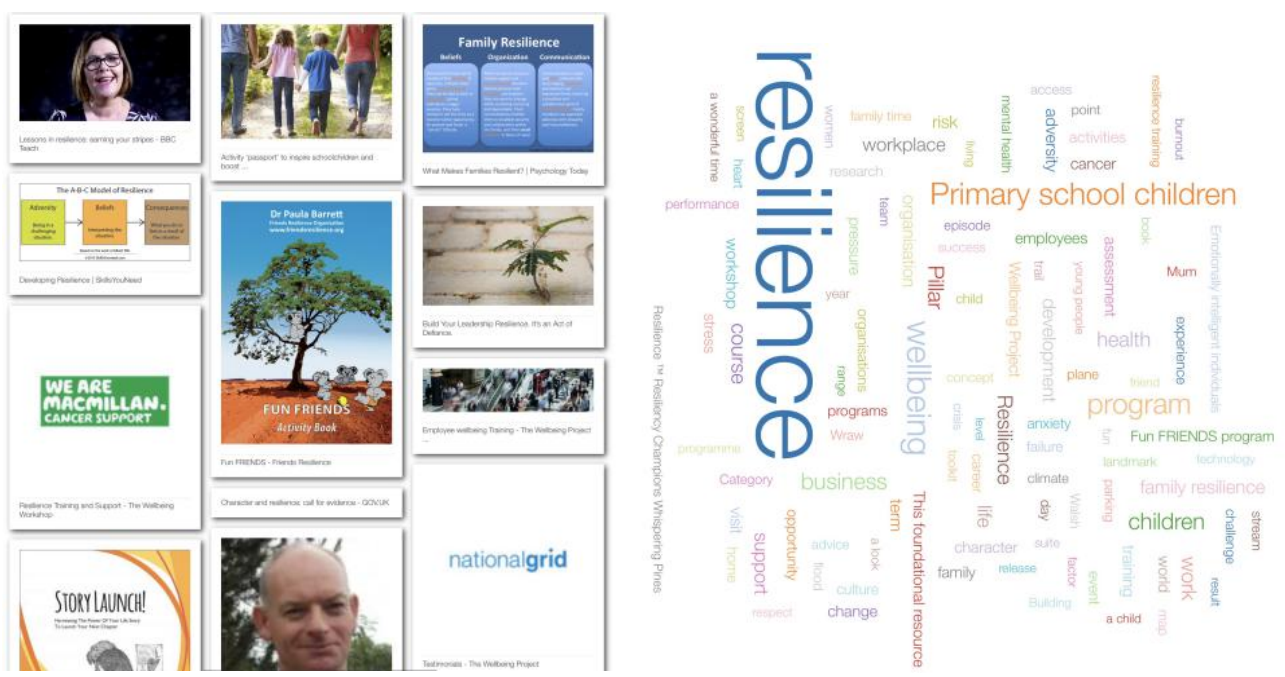

Figure 20: Topics of interest: My Resilience in the UK, June 2019 


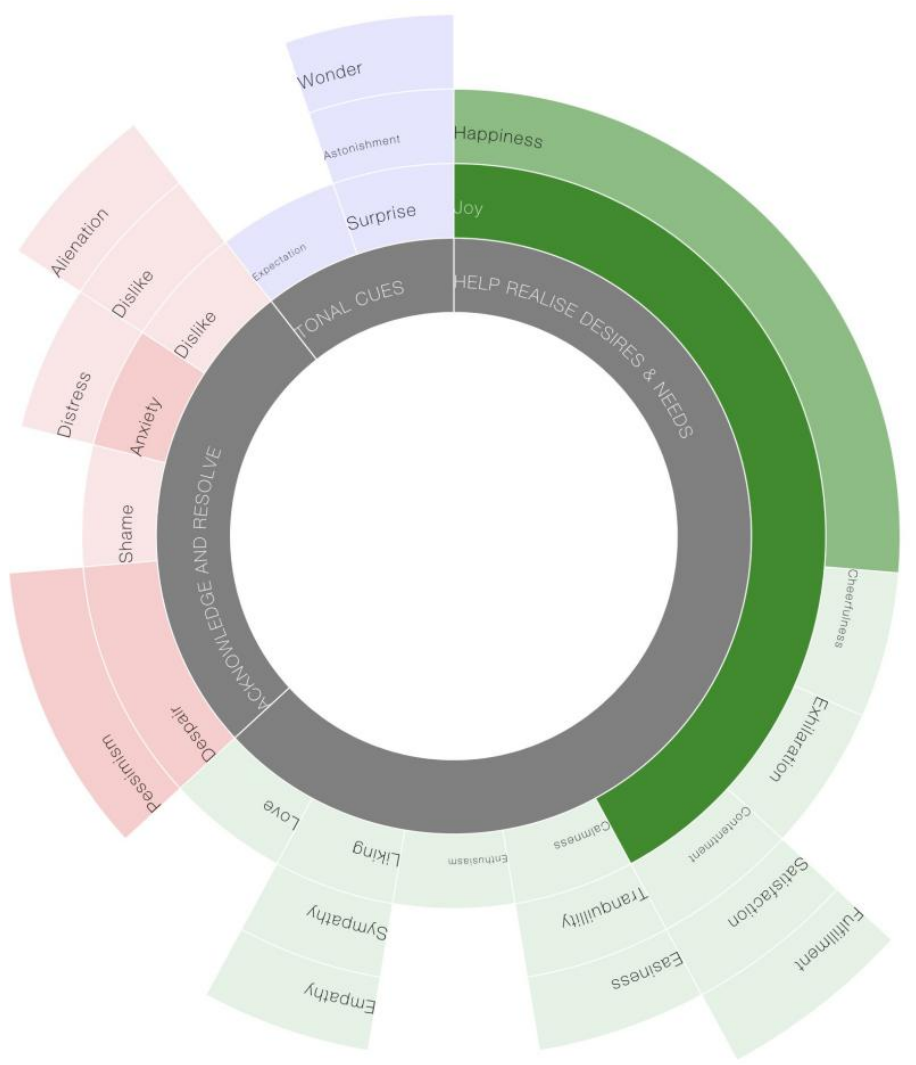

Figure 21: Emotional Response: My Resilience in the UK, December 2019

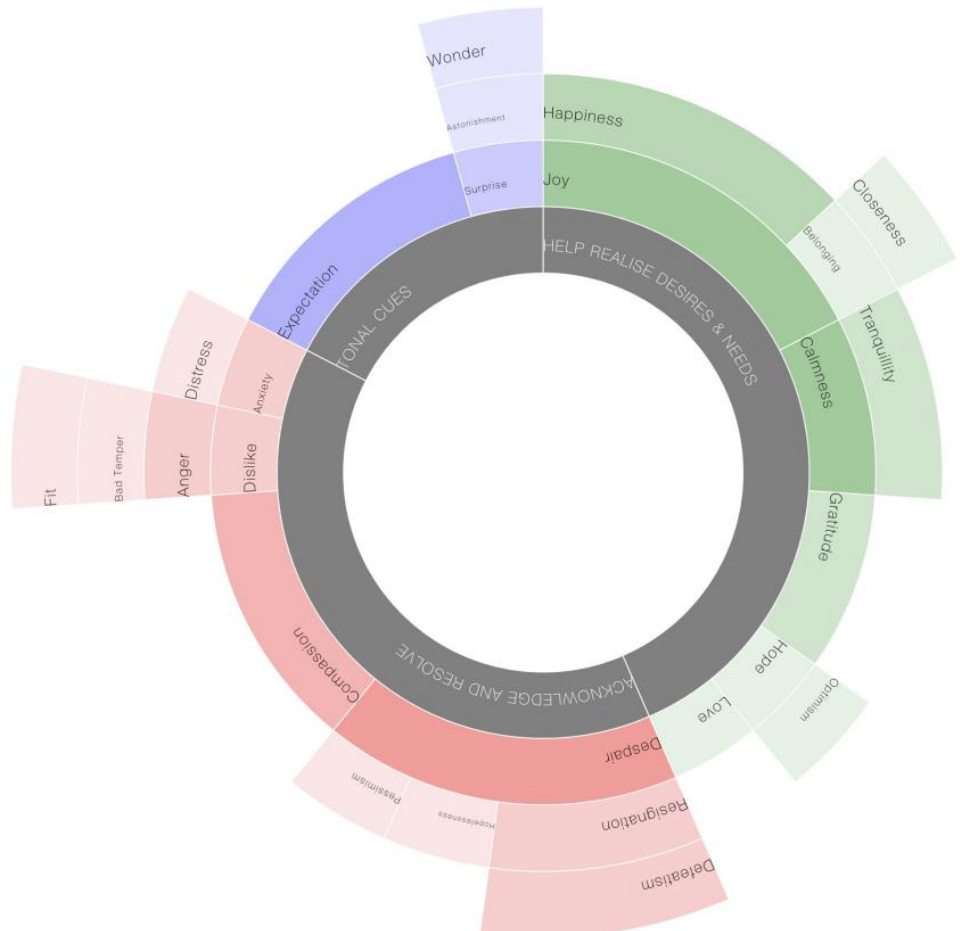

Figure 22: Emotional Response: My Resilience in the UK, April 2020 


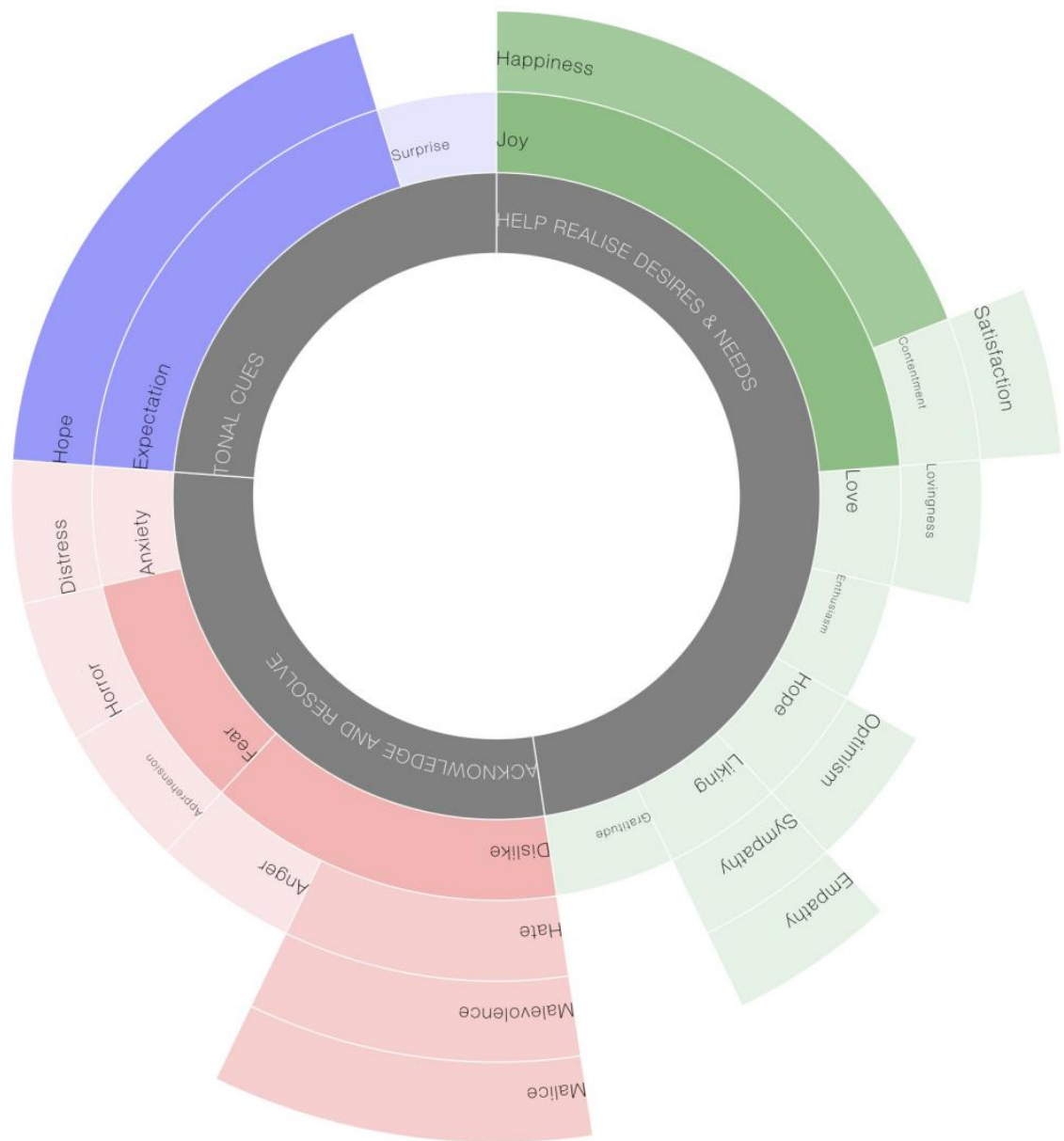

Figure 23: Emotional Response: My Resilience, in the UK, June 2020

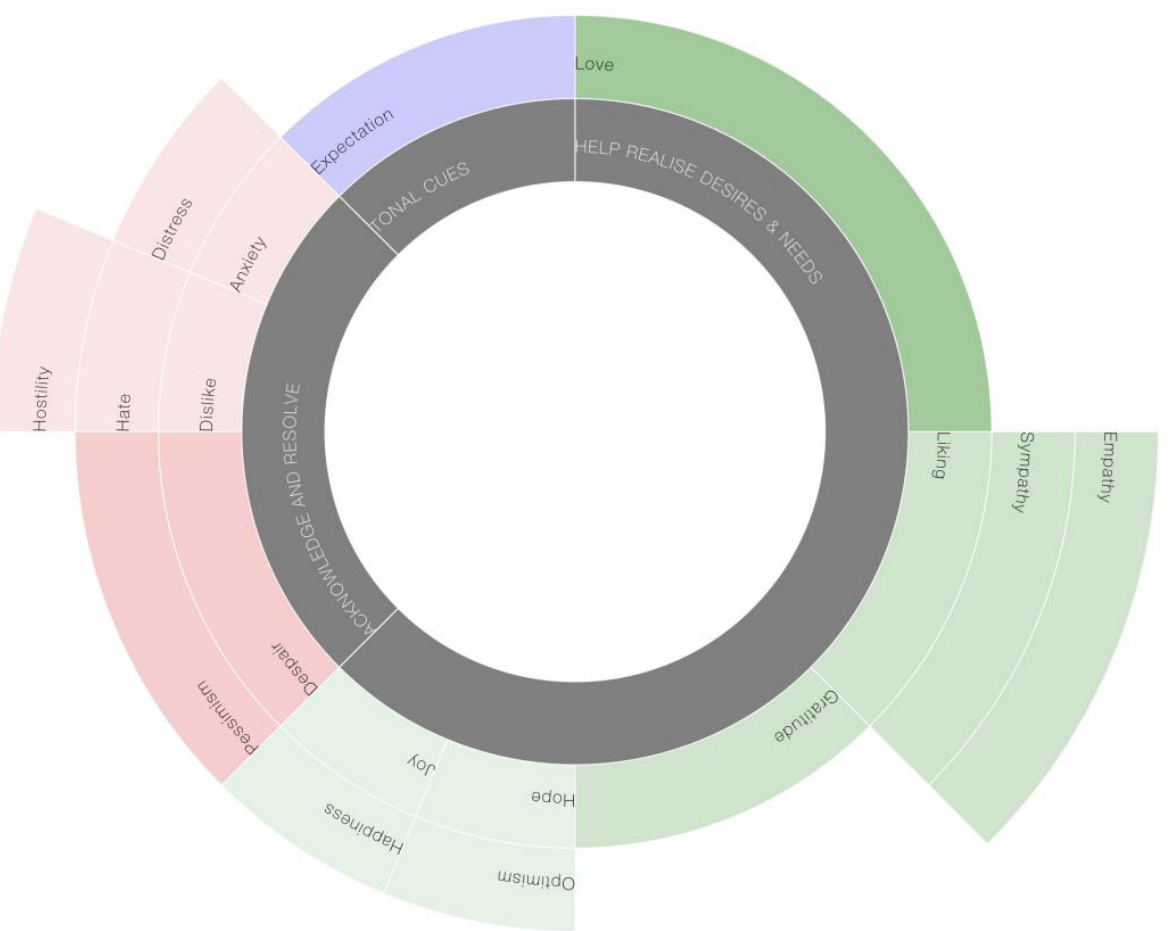

Figure 24: Emotional Response: My Resilience, in the UK, December 2020 


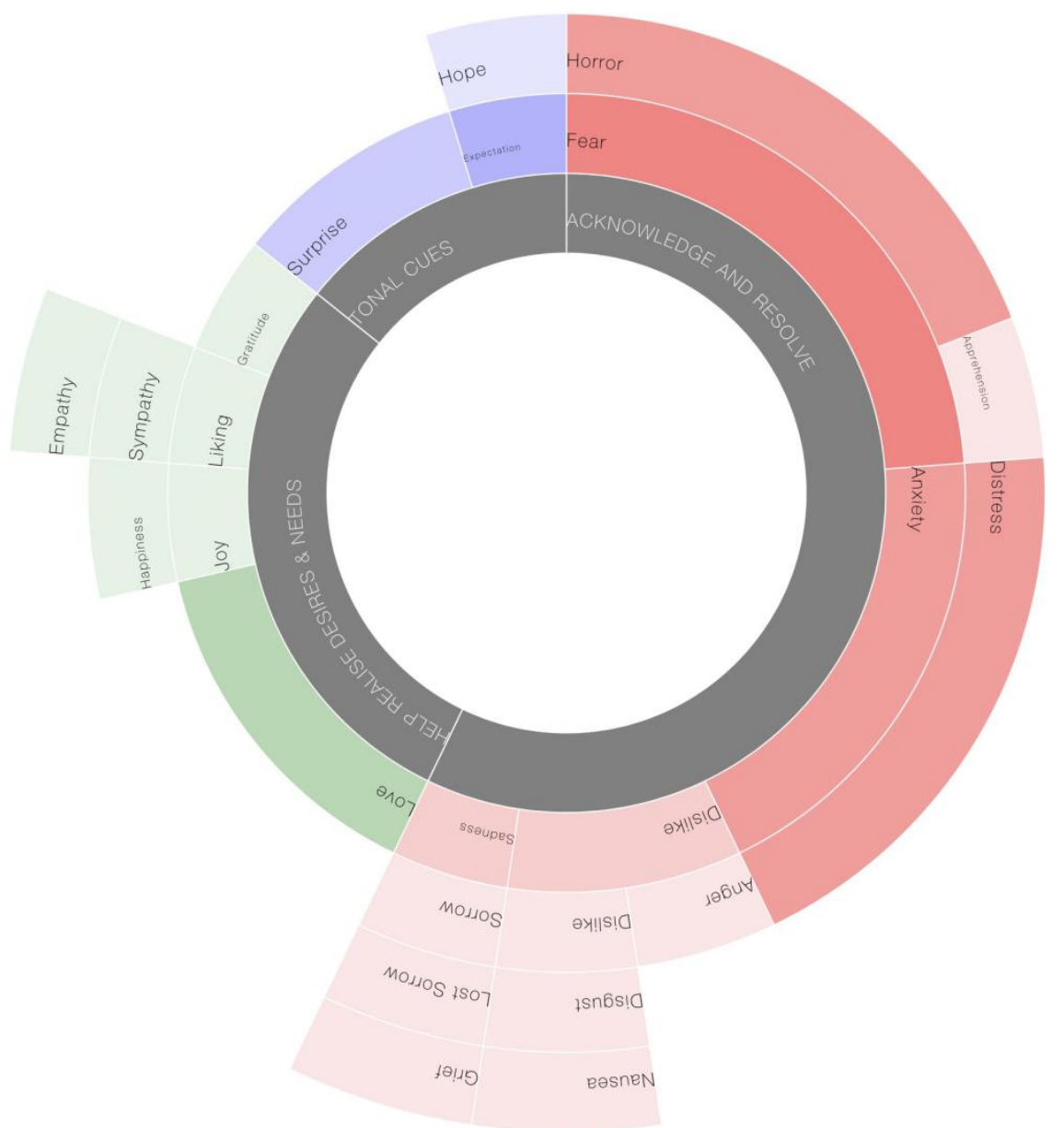

Figure 25: Emotional Response: My Resilience in the UK, June 2021

However, this situation was dramatically changed by April 2020 (Figure 22- the first national lockdown), when resignation fuel despair, as the implications of the constrained lifestyle began to take hold. There was some optimism about partnership and children, and very positive views on the NHS and the Environment Agency, but strong negativity towards (a lack of) leadership which was only heightening stress and health concerns. In June 2020 (Figure 23) fear and hope was coupled with some positive expectations and, for some a sense of common gratitude, being reflected enjoy with the coming together of families and community, to share the problem. As such there was positive emotions associated with My Resilience since it was seen as critical to personally overcoming adversity, leaving negativity associated with systems and infrastructure in respect of government work and social worker's support. This largely continued for the remainder of 2020 (Figure 24) but by June 2021 (Figure 25), peoples anger an frustration were the emotions that dominated with horror (associated with the pandemic and employment concerns), eclipsing hope with no end in sight. With the easing of the lockdown and broader vaccinations anger was diluted and optimism began to return (Figure 26) and the focus of of My Resilience became more forward looking 
and optimistic and resilience focused on climate with the momentum for COP26. Despite the rapid wave of Omicron, in December 2021, there was a sense of positivity with the booster vaccination program being accelerated.

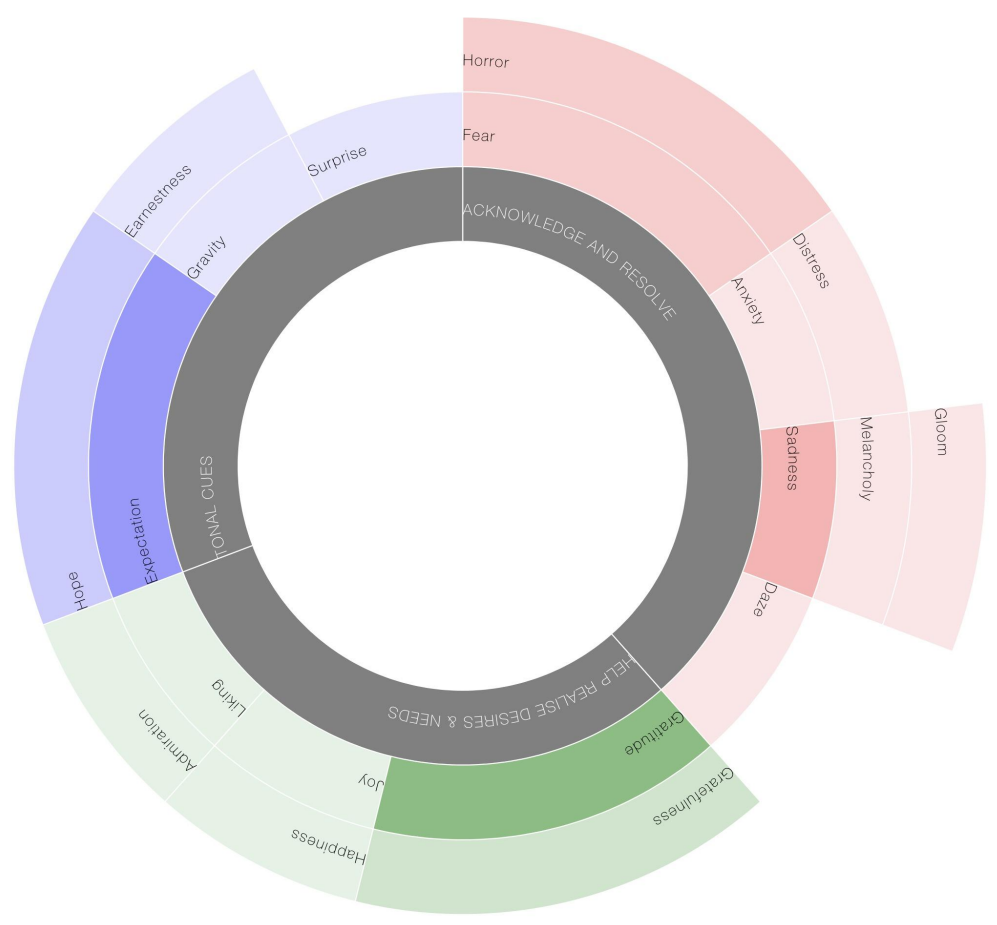

Figure 26: Emotional Response: My Resilience in the UK, August 2021

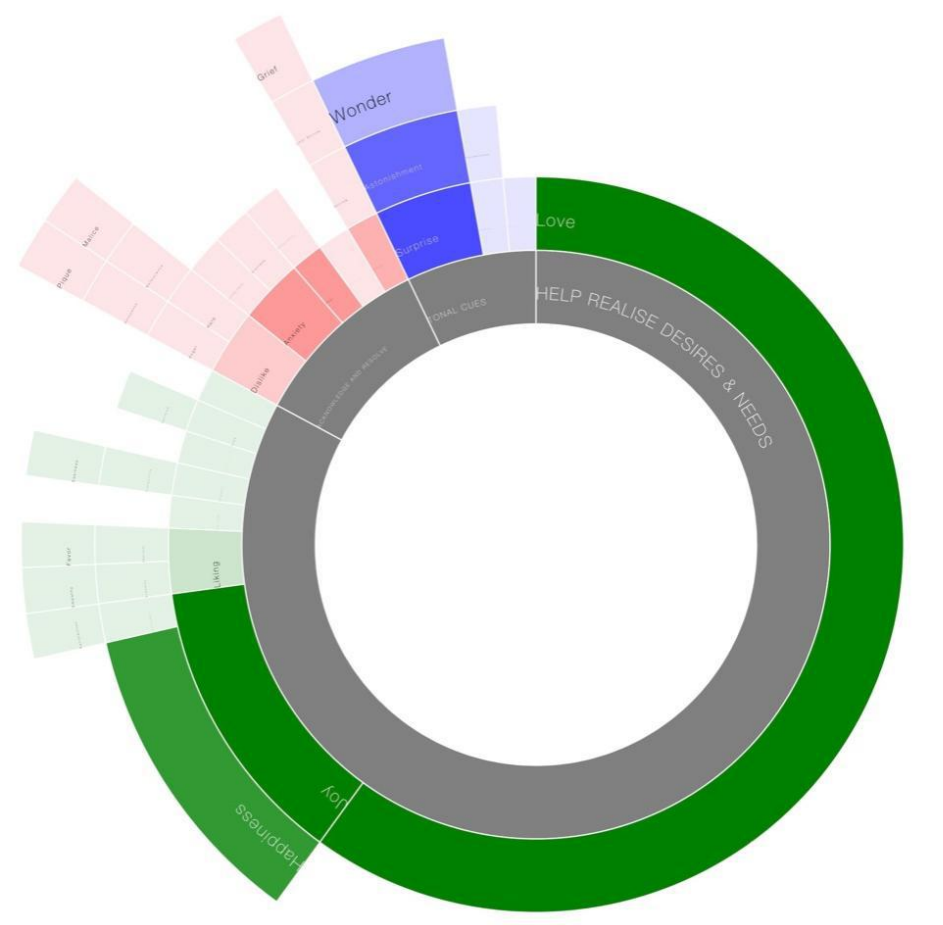

Figure 27: Emotional Response: My Resilience in the UK, December 2021 
During the COVID-19 pandemic, the response in the UK and Japan had been markedly different, but by December 2021 the emotions around My Resilience had become quite similar in both countries (Figures 15 \& 27). My Resilience, at both a personal, family and community level had become the bedrock of living with the uncertainty of new strains of COVID-19, DC.

The leadership in Japan has been cautious and slow in responding but clear communications, without a lockdown, and with strong social conformity had seen the country cope materially better than other mature markets in the west. In contrast, in the UK, confusion and fear were heightened by misinformation and a leadership narrative that had no coherence or consistency.

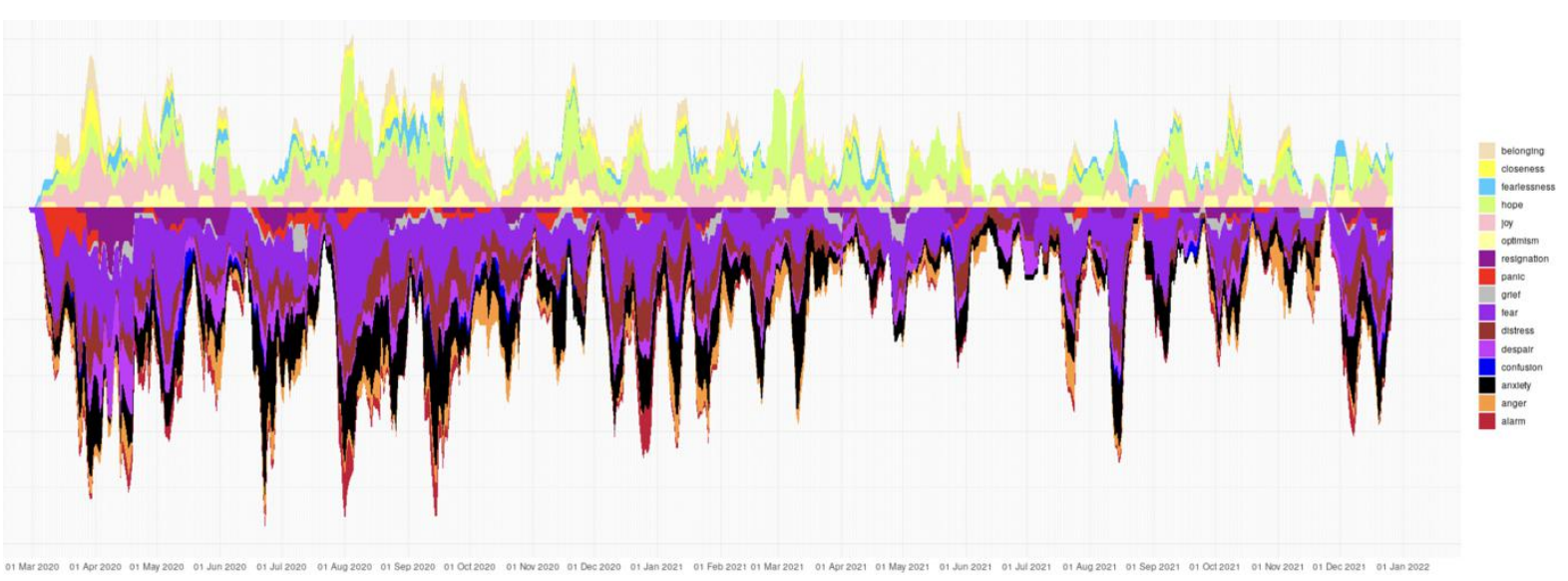

Figure 28: Daily Emotional Response to COVID-19 (March $1^{\text {st }} 2020$ to December 29 ${ }^{\text {th }} 2021$ )

One might argue that with no clear strategic leadership narrative, the confused and confusing central and local government messages only heightened the fear, anguish and anger compounding a period of uncertainty. Had the public leaders regularly tracked the emotional response around COVID-19 (Figure 28), then they would have been more in touch with the mood of the country, what was important to, and so better able to respond and project a leadership stance. Indeed, in December 2021, the actions of the Prime Minister in relation to his 2020 Christmas party, at a time when the country was in lockdown, were dominating the national news. The emotional response to this narrative was one of disgust with an affect orientation that was active and negative (as in Figure 17). It was an attack on Boris Johnson's ability to lead and was fueled by former colleagues and a sense that constant dissembling meant that leadership was disconnected from reality. Beyond the disgust was a feeling of shame and distance (Figure 29). 


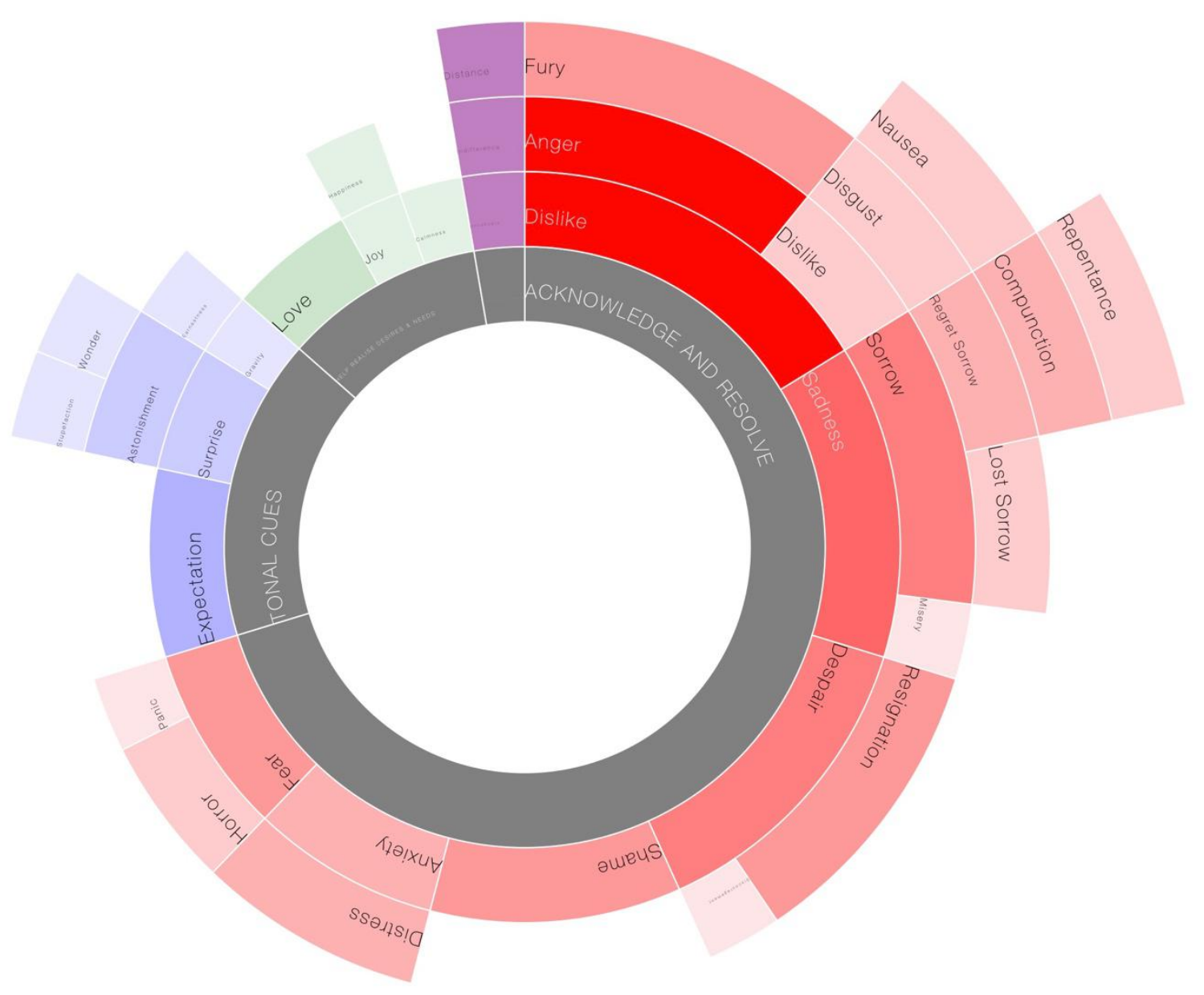

Figure 29: Emotional Response: Boris Johnson's Christmas Party narrative.

\section{Implications: Sustainability must be intentional}

We believe that taking a LifeStyle ${ }_{b y}$ Design stance will facilitate societal regeneration, and improve an individual's QOL. Design thinking is explicitly intentional. It is widely accepted that roughly 60percent of mortality and 80percent of the global disease burden are a function of just four LifeStyle choices- lack of exercise; poor nutrition; smoking and alcohol abuse. Thus, a purposeful new perspective on health insurance could for example, incentivise customers to make healthier and better choices. The basis of the risk profile simply needs to create personalized solutions facilitated by Big Data and AI. It would be assessed less on broad demographic metrics but driven by an individuals' behavior. It would be implemented with an understanding of what is important to them and their emotions, which are now considered to enhance one's reasoning [100]. 
In general, demographic trends are increasingly placing pressure on existing healthcare models around the world. A factor affecting Japan in the first instance but developing and developed economies, alike, will not be immune. A partial solution, widely adopted, in place of substantial reform, has been to ask people to take more personal responsibility for their self-medication. In parallel unprecedented medical breakthroughs can be envisaged due to the confluence of multiple factors such as Life Science maturation, big data, AI,.., which has attracted 'significant' new entrants into the traditional 'pharma' space. Such innovation needs to take place in parallel with broader social regeneration initiatives that the population can readily embrace.

This demands a receptive and educated population, with aligned expectations, that can envisage how practically and meaningfully their QOL can be enhanced. At the heart of the notion of LifeStyle by Design is the basic human right of choice- 'informed choice' to improve their lives. To enable this public and private sector and policymakers need to understand how people both think and feel, and the messages that are motivating. Communications will play an ever-increasing and pivotal role in materialising the regeneration process and realizing social innovation. It demands purposeful leadership [101] with strategic leadership narratives that engage with and inspire people.

This paper has illustrated how it is possible, for the first time by design, with the Significance Systems methodology, to identify, and understand the key drivers of engagement and wellbeing narratives that would impact key drive constituencies and orient public opinion to effect change. Landscape was chosen due to its ability to first discover, then describe topical engagement. It showed that the narratives adopted had the potential, in both Japan and the UK, to drive engagement. Timeless narratives provide an authentic perspective that different stakeholders can align with to effect regeneration. At present, while there were significant differences when comparing Japan and the UK, it was consistently found that the narratives were currently ill-defined. That said, the analyses in the paper demonstrated, in a preliminary manner, how and where powerful and motivating communications can help 'shape the narratives that can shape the world.' 


\section{References}

[1] _2025, 2021, Our world beyond 2025, https://www.2025global.com/our-worldsbeyond-2025

[2] United Nations, The 17 Goals, https://sdgs.un.org/goals

[3] TWI2050, UN Sustainable Development Solutions Network, https://www.unsdsn.org/the-world-in-2050

[4] UN Climate Change Conference, COP26, UK2021, https://ukcop26.org

[5] Jones, H., Transparency of ESG investment ratings faces regulatory scrutiny, Reuters, Nov., 242021

[6] Jones, H., ESG Book aims to 'disrupt' sustainability sector with free data, Reuters, Dec., 12021

[7] Bauck, W., Apr.,2 2021, The new buzzword in fashion, FT, Style, https://www.ft.com/content/71b58bba-e95a-4e0e-85c0-c75717bdfdbc

[8] Edelman Trust Barometer, 2021

[9] Read, M., Dec., 2021, Inaugural speech, Ad Asia 2021, Macao

[10] Polman P., \& Winston, A., 2021, Net Positive, HBR Press

[11] Net Zero Climate, https://netzeroclimate.org

[12] Nelms, B., 2020, BC, DC and AC - The heroes rarely mentioned, The Citizen, May $3^{\text {rd }}$

[13] The Truth About CSR, Rangan, VK., et al, Jan-Feb., 2015, HBR

[14] Quaadman T., The Role of ESG in the Business Community, Centre for Capital Markets, Competitiveness, US Chamber of Commerce, https://www.centerforcapitalmarkets.com/the-roleof-esg-in-the-business-community/

[15] Warden, J., 2021, What does 'Regenerative' thinking mean? RSA Journal 4, 26-31

[16] Polman P., \& Ignatius, A., (HBR Editor) Former Unilever CEO Paul Polman Says Aiming for Sustainability Isn’t Good Enough—-The Goal Is Much Higher, Interview, HBR, Business and Society, Nov., 19, 2021

[17] Davis-Peccoud J., \& Deryckere M., Oct., 4, 2021, How Sustainable Brands Add Value, Bain \& Co.,Snap Chart, https://www.bain.com/insights/how-sustainable-brands-addvalue-snap-chart/

[18] WHO Definition of Heath, Preamble to the Constitution of WHO as adopted by the International Health Conference, New York, 19 June - 22 July 1946; signed on 22 July 1946 by the representatives of 61 States (Official Records of WHO, no. 2, p. 100)

[19] Falardeau, E., et al., June 2021, Sweating for the fitness consumer, McKinsey Insights 
[20] Cross, DT., June 7 2021, To replace meat, processed plant-based food needs to be healthier and tastier, Sustainability Times, https://www.sustainability-times.com/sustainable-business/toreplace-meat-processed-plant-based-food-needs-to-be-healthier-and-tastier/

[21] Deloitte, 2021, A call for accountability and action, The Deloitte Global 2021 Millennial and Gen Z survey, Fieldwork 8 Jan-18 Feb., 2021

[22] Easterlin R., 1974. Does economic growth improve the human lot? Some empirical evidence, in Paul A. David; Melvin W. Reder (eds.). Nations and Households in Economic Growth: Essays in Honor of Moses Abramovitz. New York: Academic Press, Inc; DeNeve, J., D. Ward, G. Keulenaer, B. van Landeghem, G. Kavetsos, and M. Norton, 2018, The asymmetric experience of positive and negative economic growth; global evidence using subjective well-being data, Review of Economic Statistics: 100 (2), 362375

[23] Kapoor, A., \& Debuy, B., Oct 2019, GDP it is not a measure of human well-being, HBR,

[24] Kapp, J., July 2, 2021, Let's Double-down on Measuring What We Treasure, Global Partnership for Sustainable Development Data, The Data Values Project, https://www.data4sdgs.org/news/lets-double-down-measuring-what-we-treasure

[25] Sachdever P., Aug., 2021, Should economists consider happiness rather than GDP? Schroders, In Focus

[26] Layard, R., 2020, Can we be happier?, A Pelican Book

[27] Clark, AE., et al, 2018, The Origins of Happiness, Princetown University Press

[28] Jackson T., 2008, Where is the "wellbeing dividend"? Nature, structure and consumption inequalities, Local Environment, 13:8, 703-723, DOI: 10.1080/13549830802475625

[29] RSA, 2015, Community Capital- the value of connected communities, Connected Communities Report

[30] Beyond Imagination, https://www.beomni.ai

[31] Japan Science \& Technology Agency (JST), Aug., 2021, Early Detection and Treatment Facilitated Using Nanomachines: Guaranteed Health, Science Japan, Featured Stories, https://sj.jst.go.jp/stories/2021/s0804-01j.html

[32] Dychtwald, K., 1986, Age Power: How the 21st Century Will Be Ruled by the New Old, Putnam

[33] Stephenson N., 1994, Snow Crash, Bantam Books 
[34] Hanington, B., \& Bella, M., 2012, Universal Methods of Design: 100 Ways to research Complex Problems, Develop Innovative Ideas and Design Effective Solutions, Rockport Publishers

[35] Deloitte Digital, Oct., 2021 Launch of Ethos, https://www.prnewswire.com/news$\underline{\text { releases/deloitte-digital-launches-ethos-a-new-offering-helping-businesses-tackle-social- }}$ issues-through-innovation-301403401.html

[36] Giurge, LM., \& Bohms, V., Dec., 1 2021, Be Intentional About How You Spend Your Time Off, HBR, https://hbr.org/2021/12/be-intentional-about-how-you-spend-your-timeoff?utm_medium $=$ email\&utm_source $=$ newsletter_daily\&utm campaign $=$ dailyalert nota $\underline{\text { ctsubs \&deliveryName }=\text { DM163673 }}$

[37] Warden J., Oct., 6, 2021, Regenerative Futures. From sustaining to thriving together, RSA Report, https://www.thersa.org/reports/regenerative-futures-from-sustaining-tothriving-together

[38] Malmberg, K., \& Vaitinnen, I., (eds.,) 2017 - 2019, Living Lab Methodology Handbook, U4IoT Consortium.

[39] Tabata, N., et al., 2021, Living Lab for citizens' wellness: A case of maintaining and improving a healthy diet under the COVID-19 pandemic, Int. J. Environ. Res. Public Health 2021, 18

[40]_2025, 2021, Focus on the Sustainable Age, podcast, Spotify, https://www.2025global.com/podcast

[41] Bruner E., Cable, N., \& Iso, H., 2021, Health in Japan. Social epidemiology of Japan since the 1964 Tokyo Olympics, Oxford University Press

[42] Japan Cabinet Office, Science and Technology Policy. Council for Science, Technology and Innovation, https://www8.cao.go.jp/cstp/english/society5_0/index.html

[43] Warden, J., 2021, What is 'regenerative' thinking? RSA Journal, 4, 26-31

[44] Nakane, C., 1970, Japanese Society, Penguin Books; Nakane, C., 1977, Family-centred Human Relationships, Kodansha; Kawai, H., 1980, Examination of Family Relationships, Kodansha

[45] Cabinet Office, Govt., of Japan, The Annual Report on Ageing Society Japan 2019, 1133

[46] Cable, N., Sekine, M., \& Koike, S., 2021, Family, Community and Mental Well-being, in Health in Japan, Social Epidemiology of Japan since the 1964 Tokyo Olympics, Brunner, E., Cable, E., \& Iso, H.,[eds.,]] 
[47] Cable, N., et al.,2016, Factors noted in other comparative national studies including Japan mental health: evidence from civil servant studies across Great Britain, Japan and Finland, Public Health, 137;139-146

[48] Aida, J., et al., 2018, Social and behavioural determinants of the difference in survival among older adults in Japan and England, Gerontology 64(3),266-277

[49] The Mainichi, Dec., 11, 2021, Japanese peoples core beliefs disrupted amid COVID; study, original by Yudai Hiraka, Sendai Bureau

[50] Dunbar, RIM., 2017, Breaking Bread: the functions of social eating, Adaptive Human Behaviour and Physiology, 3, 198-211]. Raj [Raj, M., Oct., 2021, What's on the menu matters in healthcare for diverse patients, The Conversation, Health + Medicine, https://theconversation.com/whats-on-the-menu-matters-in-health-care-for-diversepatients-166931

[51] The Economist, 2021, What the world can learn from Japan, Leaders, Dec $11^{\text {th }}$

[52] Hofstede, G., 2001, Culture's Consequences: comparing values, behaviors, institutions, and organizations across nations (2nd ed.), SAGE

[53] Miralles F., \& GarciaH., 2016, Ikigai: The Japanese Secret to a Long and Happy Life, Penguin Books

[54] Lieven, A., 2021, Climate Change and the Nation State; the realist case, Allen Lane, $202 \mathrm{pp}$

[55] Gelfand M J et al., The relationship between cultural tightness-looseness and COVID-19 cases and deaths: a global analysis, Lancet Planet Health, Published Online, (January 29, 2021) https://doi.org/10.1016/ S2542-5196(20)30301-6

[56] Melton, J., \& Sinclair, R., 2021, Culture and COVID-19: A Global Analysis of the Successes of Collectivist Countries and the Failures of Individualistic Countries.,41pp,https://www.researchgate.net/publication/355749968_Culture_and_CO VID19_A_Global_Analysis_of_the_Successes_of_Collectivist_Countries_and_the_Failu res_of_Individualistic_Countries

[57] Erman., A., \& Medeiros, M., 2021, Exploring the Effect of Collective Cultural Attributes on Covid-19-Related Public Health Outcomes, Front. Psychol., https://doi.org/10.3389/fpsyg.2021.627669

[58] The World Bank, Aug., 3, 2021, 'Absolutely Unacceptable' COVID-19 Vaccination Rates in Developing Countries, The Development Podcast, https://www.worldbank.org/en/news/podcast/2021/07/30/-absolutely-unacceptablevaccination-rates-in-developing-countries-the-development-podcast 
[59] Sakamoto, H., et al., Assessment of Suicide in Japan During the COVID-19 Pandemic vs Previous Years, JAMA Network Open: Feb., 2, 2021, doi:10.1001/jamanetworkopen.2020.37378.

[60] IQVIA sponsored survey of Oncologists, Hem-oncologists and Onco-surgeons, Feb 2021, The impact of COVID-19 on cancer treatment in the EU4 \& UK, https://www.iqvia.com/library/publications/the-impact-of-covid-19-on-cancer-treatmenteu5-report

[61] O'Hara., M., 2020, The Shame Game, Policy Press

[62] House of Commons, Nov., 8 2021, Housing, Communities and Local Government Committee Oral evidence: Work of the Department 2021, HC 818, https://committees.parliament.uk/oralevidence/2980/html/

[63] Press release, Dec., 7, 2021, Ofsted Annual Report: We must do all we can to make sure this generation is not denied its opportunities, https://www.gov.uk/government/news/ofsted-annual-report-we-must-do-all-we-can-tomake-sure-this-generation-is-not-denied-its-opportunities

[64] Gold, J., May 2020, Could COVID-19 Finally Destigmatize Mental Illness?, TIME

[65] World Health Organisation, for 10-10-2020, World Mental Health Day, COVID-19 disrupting mental health services in most countries, WHO survey, released 5-10-2020

[66] Ikegami, N., et al., 2011, Japanese universal health coverage evolution: evolution, achievements and challenges, Lancet, 378(9796), 1106-1115

[67] Brock, M., 2022, Ten Japan trends to watch in 2022, Asia Nikkei, Jan., $5^{\text {th }}$

[68] The Fifth Basic Plan for Gender Equality: Toward a Reiwa Society Where All Women and Girls Can Thrive and Achieve Their Full Potential, Japan Labor Issues, vol.5, (33), August-September 2021

[69] Japan Cabinet Office, 2020

[70] Nippon.com, Dec., 10, 2021, Ishihara resigns as special advisor to Kishinev cabinet, Politics

[71] NHK World, Dec., 10 $0^{\text {th }}, 2021$, Corruption scandal rocks Japanese university, Back Stories, https://www3.nhk.or.jp/nhkworld/en/news/backstories/1840/

[72] Benes N., Sept., 21 2021, A crucial change is needed to improve corporate governance in Japan, FT, https://www.ft.com/content/d1f44a32-9e08-4a54-a0b1-38552b74236d

[73] Asian Corporate Governance Association (ACGA,) Nov., 2020, Future Promise, Aligning governance and ESG in Asia, Special Report, Sponsored by CLSA 
[74] Japan Times, Dec., 1, 2021,

https://www.japantimes.co.jp/news/2021/12/01/national/crime-legal/france-kidnappingjapan-children/

[75] Oliveira, R., et., 2021, Towards prosocial design: A scoping review of the use of robots and virtual agents to trigger prosocial behaviour, rather than just industrial process engineering, in an ageing society, Computers in Human Behaviour, 114, https://doi.org/10.1016/j.chb.2020.106547

[76] International Home Care \& Rehabilitation Online Exhibition, 2021, https://www.hcrweb.or.jp/login, 2022 https://hcr.or.jp

[77] Huber M., How should we define health? BMJ (2011);343:d4163;

[78] Huber M., et al., Towards a "Patient-Centred" Operationalisation of the New Dynamic Concept of Health: A Mixed Methods Study. BMJ Open, 6(1), (2016) e01009

[79] The Economist, 2021, Dramatic growth in mental-health apps has created a risky industry, Psyber Boom, Dec., $11^{\text {th }}$ edition

[80] Beaumont CD., 2021; Social Sharing and Ongoing Narratives Provide Potential Pathways to Enhance Daily Health: Timely Perspectives from the UK and Japan (LifeStyle by Design: Virtual Living Lab). Int J Environ Sci Nat Res., 27(2): 556206. DOI: $10.19080 / I J E S N R .2021 .27 .556206$

[81] Global Innovation Index, GII, Sept 202, https://www.wipo.int/global_innovation_index/en/2021/

[82] Drucker, PF., 2001, Essential Drucker, Routledge

[83] Beaumont, CD., et al., 2021, 'Engaging with Engagement': a new communications strategy that provides coherence making companies more competitive and public institutions more agile and accessible, Advances in Journalism and Communication, 2021, 9, 161-195

[84] McLuhan M., \& Foire Q., 1967, The medium is the massage. An inventory of effects, Bantam Books;

[85] Riley, C., 2017, After the Mass-Age; Analog: Norwood, US (In English and Japanese

[86] Gratton, L., \& Scott, A., 2016, The 100-year Life, Bloomsbury Business;

[87] Carstensen, LL., Nov., 2021, The new Map of Life, The Stanford Center on Longevity, $18 \mathrm{pp}$

[88] Saraev, V., et al., 2021, The value in the mental health of Woodlands, Forest Research

[89] Forbes, 2010; https://www.forbes.com/sites/jeffbercovici/2010/12/09/who-coined-socialmedia-web-pioneers-compete-for-credit/\#1fada0c151d5 
[90] Lator, B., 2005, Reassembling the social; an introduction to Actor-Network-Theory, Oxford Union Press

[91] https://kyotoprize.org/en/2021/

[92] Mulgen, G., 2021 The case for exploratory social sciences, 24pp., The New Institute, Foundation $\mathrm{gGmbH}$

[93] Beaumont, CD., \& Ricketts, J., (2020) A Significant Moment in History: a virtual Living Lab., LifeStyle narratives that are shaping our world; the cases of Japan and UK 2019-20, Sustainability, 12(22), 9658; Special Issue: Big Data, Knowledge Management and IoT: New Perspectives for New Challenges in Disruptive Times

[94] Shiller, J., 2019, Narrative Economics: How Stories Go Viral and Drive Major Economic Events, Princetown University Press

[95] Parkinson B, \& Mansted, ASR., 2015, Current Emotion Research in Social Psychology: Thinking About Emotions and Other People, Emotion Review,7 (4), 371-380; Emotion Researcher; ISRE's Sourcebook for Research on Emotion and Affect, http://emotionresearcher.com

[96] Pekrun, R., \& Linnenbrink-Garcia, L., (eds.,) 2014, Routledge

[97] developer- Complete Coherence

[98] Changing Minds, http://changingminds.org/explanations/evolution/plutchnik postulates.htm\#nav

[99] The Japan Times, Dec., 13 ${ }^{\text {th }} 2021$, Japan's low COVID-19 death rate may be due to genetics, top research institute says

[100] Mlodinow L., Jan., $5^{\text {th }}$ 2022, More than a feeling: why emotions are crucial to how we think, The Guardian, Opinion, Neuroscience, https://www.theguardian.com/commentisfree/2022/jan/05/emotions-crucial-to-how-wethink-charles-darwin-decision-making

[101] Shah, O., 2022, We don't have a climate crisis, we have a leadership crisis, Interview with Paul Polman, The Sunday Times, Jan., $9^{\text {th }}$, https://www.thetimes.co.uk/article/paulpolman-unilever-leadership-crisis-interview-nddf8fmnm 